MESTRADO INTEGRADO EM MEDICINA

\title{
O Papel da Biópsia Líquida no Cancro da Próstata Metastizado
}

Joana Andrade Glória

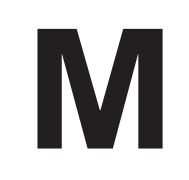

2019 


\title{
U.PORTO
}

INSTITUTO DE CIÊNCIAS BIOMÉDICAS ABEL SALAZAR

UNIVERSIDADE DO PORTO

Instituto de Ciências Biomédicas Abel Salazar - Universidade do Porto

Mestrado Integrado em Medicina - 2018/2019

\author{
Dissertação - Artigo de Revisão Bibliográfica
}

\section{O Papel da Biópsia Líquida no Cancro da Próstata Metastizado}

\author{
Joana Rita Andrade Glória \\ Aluna do 60 ano do Mestrado Integrado em Medicina do Instituto de Ciências Biomédicas Abel Salazar \\ e-mail: joana_gloria_@hotmail.com
}

Orientador: Professor Doutor Avelino Fraga

Assistente Graduado Sénior de Urologia no Centro Hospitalar Universitário do Porto

Professor Catedrático Convidado do Instituto de Ciências Biomédicas Abel Salazar

Coorientador: Dr. Diogo Nunes Carneiro

Interno de Formação Específica de Urologia no Centro Hospitalar Universitário do Porto

Porto, Maio de 2019 
Instituto de Ciências Biomédicas Abel Salazar - Universidade do Porto

Mestrado Integrado em Medicina - 2018/2019

Dissertação - Artigo de Revisão Bibliográfica

O Papel da Biópsia Líquida no Cancro da Próstata Metastizado

Autor: Joana Rita Andrade Glória

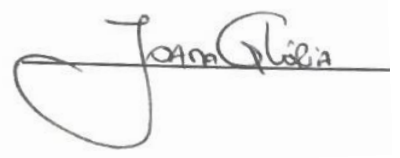

Orientador: Professor Doutor Avelino Fraga

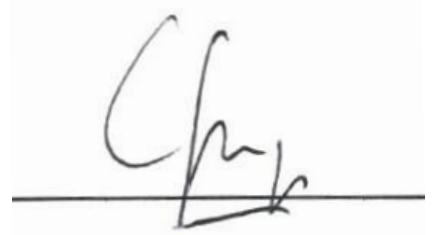

Coorientador: Dr. Diogo Nunes Carneiro

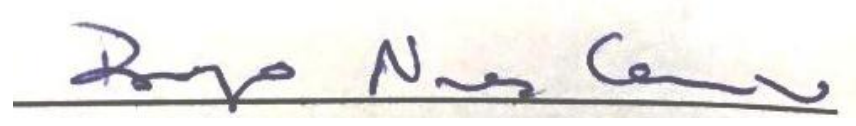

Porto, Maio de 2019 


\section{Resumo}

O cancro da próstata é a segunda neoplasia maligna mais frequente nos homens em todo o mundo. A elevada prevalência do cancro da próstata, bem como o seu curso clínico relativamente indolente e as opções terapêuticas emergentes, conduziram à necessidade de identificação de biomarcadores que possam auxiliar nas decisões clínicas e refletir a resposta aos tratamentos.

"Biópsia líquida" é um termo genérico aplicado ao estudo de biomarcadores atribuídos aos tumores, que se encontram em circulação nos fluídos corporais de doentes com cancro. Baseia-se no princípio de que nestes doentes existem células tumorais e fragmentos com conteúdo genómico de células tumorais que entram em circulação e que podem ser detetados e usados como biomarcadores para aplicação clínica.

O objetivo deste trabalho de revisão bibliográfica é descrever o papel atual da biópsia líquida no contexto do cancro de próstata metastizado e de que forma a incorporação de tais análises constitui uma promessa para a estratificação de risco nestes doentes, permitindo uma melhor seleção de tratamento, bem como uma abordagem de medicina personalizada.

A metodologia usada consistiu na revisão de literatura relevante existente sobre o papel da biópsia líquida no cancro da próstata metastizado. A pesquisa foi realizada entre os meses de setembro de 2018 e Fevereiro de 2019 no motor de busca "Pubmed", para trabalhos publicados nos últimos 10 anos na língua inglesa, realizados em humanos, incluindo artigos de investigação original e de revisão bibliográfica. Dos artigos obtidos após a aplicação dos filtros foram selecionados os considerados relevantes, especialmente segundo o título e através do resumo disponível. Também foi feita pesquisa direta de artigos mencionados na bibliografia consultada, sempre que tal pareceu relevante. Da bibliografia encontrada foram selecionados os estudos e revisões com relevância para o tema.

A maioria dos biomarcadores correlaciona-se com a carga tumoral, sendo mais frequentemente identificados em indivíduos com doença disseminada. Os biomarcadores mais estudados em doentes com cancro da próstata podem ser subdivididos em três grandes grupos: células tumorais circulantes, material genético livre (como RNA e DNA - designadamente, microRNA e DNA livre circulante) e vesículas extracelulares (onde há inclusão de material específico e único do tumor). Este conhecimento pode permitir desenvolver potenciais aplicações clínicas desde o diagnóstico ao prognóstico, bem como o desenvolvimento de biomarcadores preditivos de resposta aos tratamentos e de monitorização da doença.

Palavras-chave: Cancro da próstata, Biópsia líquida, Células Tumorais Circulantes, DNA livre circulante, DNA tumoral livre circulante, microRNA, Vesículas extracelulares 


\section{Abstract}

Prostate cancer is the second most common malignancy in men. The high prevalence of prostate cancer, as well as its relatively indolent clinical course and the emerging therapeutic options, have led to the need to identify biomarkers that may aid in clinical decisions and may reflect response to treatments.

"Liquid biopsy" is a generic term applied to the study of biomarkers attributed to tumors that are circulating in the body fluids of cancer patients. It relies on the principle that in these patients there are tumor cells and fragments with genomic content of tumor that circulate and can be detected and used as biomarkers for clinical application.

The aim of this review is to describe the current role of liquid biopsy in the context of metastatic prostate cancer and how the incorporation of such analyzes constitutes a promise for risk stratification in these patients, allowing a better selection of treatment, as well as an individualized medicine approach.

The methodology consisted in the review of relevant literature about the role of liquid biopsy in metastatic prostate cancer. The research was conducted between September 2018 and February 2019 in the "Pubmed" database, for articles published in the last 10 years in English, carried out in humans, including original research articles and review articles. From the articles obtained after the application of the filters were selected those considered relevant, especially according to the title and through the available abstract. Direct research of articles mentioned in the bibliography consulted was also done, whenever this seemed relevant. From the bibliography found were selected the studies and reviews with relevance to the theme.

Most of these biomarkers correlate with tumor burden and are most often identified in individuals with metastatic disease.

The most studied biomarkers in prostate cancer patients can be subdivided into three major groups: circulating tumor cells, free genetic material (such as RNA and DNA - namely, microRNA and circulating free DNA) and extracellular vesicles (where there is inclusion of specific material and single tumor).

This knowledge may allow the development of potential clinical applications from diagnosis to prognosis, as well as the development of predictive biomarkers of response to treatment and disease monitoring.

Keywords: Prostate cancer, Liquid biopsy, Circulating tumor cells, Cell-free DNA, Circulating free tumor DNA, microRNA, Extracelullar vesicles 


\section{Abreviaturas}

ADT - Terapêutica de privação androgénica (do inglês, Androgen Deprivation Therapy)

AR - Recetor dos androgénios (do inglês, Androgen Receptor)

AR-V7 - Variante 7 do recetor dos androgénios (do inglês, Androgen Receptor Variant 7)

BRCA1 - do inglês, Breast Cancer Gene 1

BRCA2 - do inglês, Breast Cancer Gene 2

cfDNA - DNA livre circulante (do inglês, cell-free DNA)

cftDNA - DNA tumoral livre circulante (do inglês, circulating free tumor DNA)

CK - citoqueratina (do inglês, Cytokeratin)

CTCs - Células Tumorais Circulantes

DAPI - 4',6'-diamino-2-fenil-indol

DNA - Ácido Desoxirribonucleico (do inglês, Deoxyribonucleic Acid)

EpCAM - Molécula de adesão das células epiteliais (do inglês, Epithelial Cell Adhesion Molecule)

EVs - Vesículas Extracelulares (do inglês, Extracellular Vesicles)

FDA - Food and Drugs Administration

LDH - lactato desidrogenase

mCSPC - Cancro da próstata metastizado sensível à castração (do inglês, metastatic CastrationSensitive Prostate Cancer)

mCRPC - Cancro da próstata metastizado resistente à castração (do inglês, metastatic CastrationResistant Prostate Cancer

miRNA - micro RNA

mRNA - RNA mensageiro

PARP - Polimerase Poli Adenosina Difosfato Ribose (do inglês, Poly (ADP-ribose) polymerase)

PSA - Antigénio Específico da Próstata (do inglês, Prostate-Specific Antigen)

PTEN -Homólogo da Fosfatase e da Tensina (do inglês, Phosphatase and Tensin Homolog)

RNA - Ácido Ribonucleico (do inglês, Ribonucleic Acid)

TMPRSS2 - Protease Transmembranar Serina 2 (do inglês, Transmembrane Protease Serine 2) 


\section{Índice}

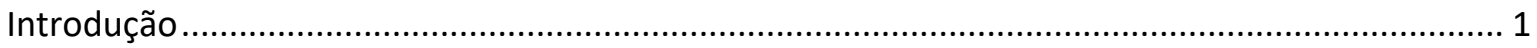

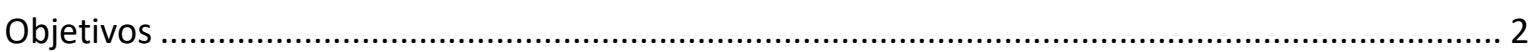

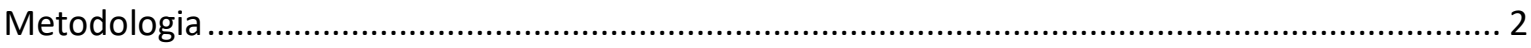

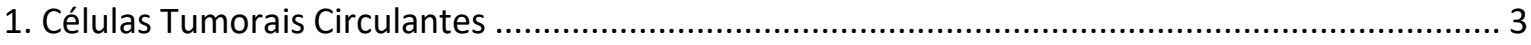

1.1 Identificação, isolamento e enriquecimento das CTCs …....................................................... 3

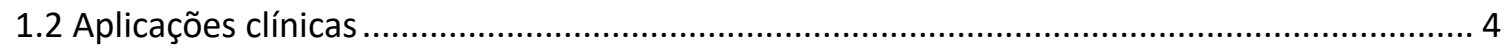

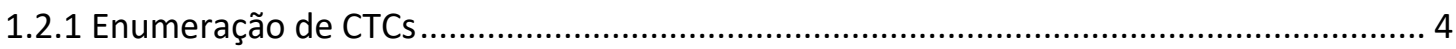

1.2.2 Identificação de fenótipos e caracterização das CTCS ..................................................... 6

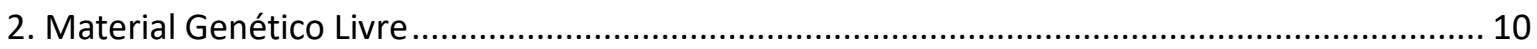

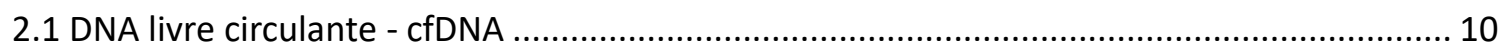

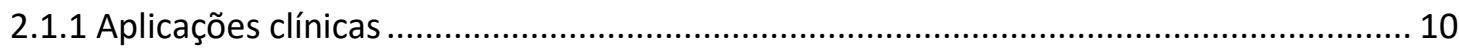

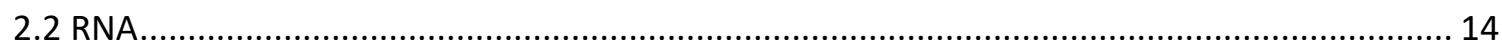

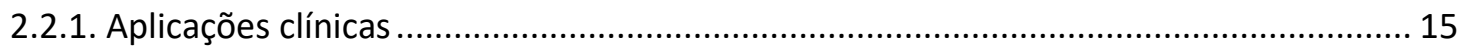

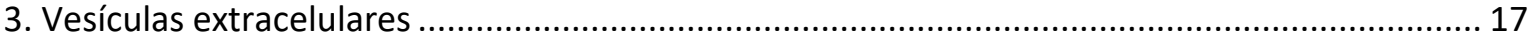

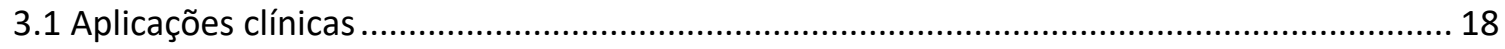

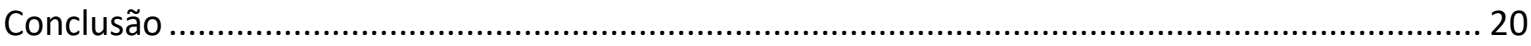

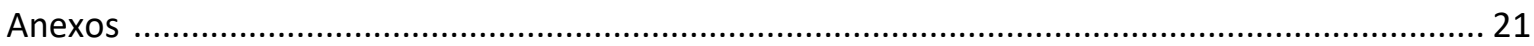

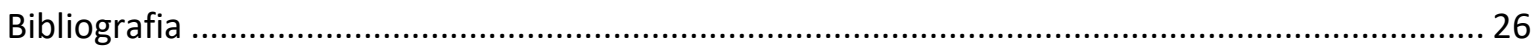




\section{Introdução}

De acordo com a Organização Mundial da Saúde, através de dados publicados pela Agência Internacional para a Investigação do Cancro, em 2018 o cancro da próstata foi o 3 mais incidente no mundo. Estima-se que em 2018 houve cerca de 1,3 milhões de novos casos de cancro da próstata e 359.000 mortes atribuíveis a esta neoplasia, sendo o 2 o cancro mais frequente e a $5^{a}$ principal causa de morte por cancro no sexo masculino. É o cancro mais frequentemente diagnosticado entre os homens em mais da metade dos países do mundo (105 de 185) (1).

O aumento da incidência de cancro de próstata nas últimas décadas tem sido fortemente influenciado pelo diagnóstico da doença assintomática, especialmente pela análise do PSA (Antigénio Específico da Próstata) sérico como teste de rastreio. Já as taxas de mortalidade por cancro de próstata têm diminuído, o que tem sido atribuído ao diagnóstico precoce, bem como a melhores tratamentos disponíveis (o que também resulta numa maior sobrevida para alguns homens com doença metastática) (1).

Nos doentes que se apresentam com doença clinicamente localizada as opções terapêuticas são curativas e a taxa de sobrevida aos 10 anos é superior a 90\%. No entanto, alguns doentes já apresentam doença metastática por altura do diagnóstico, e outros recidivam com doença metastática após terapêutica local. O cancro da próstata metastático é primeiramente abordado com terapêutica de privação androgénica (ADT). No entanto, a progressão para a resistência à castração é praticamente inexorável (2). Ainda assim, a evolução do cancro da próstata é indolente, mas com uma grande variabilidade inter-indivíduo. As alterações somáticas ocorrem ao longo da evolução da doença e com a exposição às terapêuticas (3). Para documentar essa heterogeneidade no panorama genómico em evolução do cancro de próstata seriam necessárias biópsias seriadas de tecido, o que é difícil de executar na prática clínica (4). Uma amostra de tecido obtida num determinado local do tumor, num determinado momento não é capaz de representar todo o perfil molecular da doença. Para além disso, a obtenção de biópsias sequenciais dos múltiplos locais metastizados em vários momentos ao longo do curso da doença pode não ser exequível. Neste sentido, o estudo de biomarcadores no sangue periférico representa um meio de obtenção de material tumoral que possa caracterizar as alterações presentes na doença (3).

A "biópsia líquida" é o termo genérico aplicado ao estudo das células tumorais e dos ácidos nucleicos atribuídos aos tumores nos fluídos corporais de doentes com cancro. Baseia-se no princípio de que nos doentes com cancro existem células tumorais e fragmentos com conteúdo genómico que entram em circulação e que nesse sentido podem ser detetados e usados como biomarcadores para aplicação clínica (4). 
A biópsia líquida, sendo obtida através de uma amostra sanguínea, é minimamente invasiva e permite a monitorização em tempo real da resposta ao tratamento (3). Para além disso, o uso de biomarcadores permite uma avaliação longitudinal, com monitorização sequencial da resposta e da progressão, com potencial modificação da estratégia terapêutica baseada nas alterações observadas (5).

Os biomarcadores mais estudados em doentes com cancro da próstata podem ser subdivididos em três grandes grupos: células tumorais circulantes (CTCS), material genético livre (RNA e DNA designadamente, microRNA (miRNA) e DNA circulante livre (cfDNA)) e vesículas extracelulares (EVs) (onde há inclusão de material específico e único do tumor), que podem ser purificados a partir dos fluídos corporais e analisados, para que possam ser quantificados e identificadas mutações específicas do tumor, variações no número de cópias, rearranjos de genes e outras anomalias genéticas atribuíveis ao tumor (4).

Este conhecimento pode permitir desenvolver potenciais aplicações clínicas desde o diagnóstico, prognóstico, biomarcadores preditivos de resposta aos tratamentos e monitorização da doença.

\section{Objetivos}

O objetivo deste trabalho de revisão bibliográfica é descrever o papel atual da biópsia líquida no contexto do cancro de próstata metastizado e de que forma a incorporação de tais análises constitui uma arma para a estratificação de risco nestes doentes, permitindo uma melhor seleção de tratamento, bem como uma abordagem de medicina individualizada.

\section{Metodologia}

A metodologia usada consistiu na revisão de literatura relevante existente sobre o papel da biópsia líquida no cancro da próstata metastizado. Para isso procedeu-se a uma pesquisa no motor de busca "Pubmed", utilizando as palavras-chave: "prostate cancer", "liquid biopsy", "biomarker", "circulating tumor cells", "CTCs", "cell-free DNA", "cfDNA", "circulating free tumor DNA", "cftDNA", "microRNA", "miRNA", "extracelullar vesicles", para trabalhos publicados nos últimos 10 anos na língua inglesa, realizados em humanos, incluindo artigos de investigação original e de revisão bibliográfica. Dos artigos obtidos após a aplicação dos filtros foram selecionados os considerados relevantes para a concretização da revisão bibliográfica proposta, especialmente segundo o título, bem como através do resumo disponível. Também foi feita pesquisa direta de artigos mencionados na bibliografia consultada, sempre que tal pareceu relevante. Da bibliografia encontrada foram selecionados os estudos e revisões com relevância para o tema. 


\section{Células Tumorais Circulantes}

As CTCs foram identificadas pela primeira vez em 1869 por Ashworth (6). Apesar de identificadas há mais de 150 anos (6), só mais recentemente é que o seu potencial tem vindo a ser explorado, principalmente devido ao desenvolvimento de novas técnicas para o seu isolamento e identificação.

As CTCS são células do tumor primário ou de metástases que são libertadas na corrente sanguínea e que podem ser quantificadas e usadas para a análise genómica e fenotípica do tumor (3).

Apesar de se considerar que são essenciais para o desenvolvimento da doença metastática, os mecanismos específicos que impulsionam e permitem a proliferação das CTCs permanecem pouco compreendidos. Embora já se tenha demonstrado que as CTCs têm potencial metastático, nem todas as CTCS estão destinadas a formar metástases, sendo necessários outros fatores adicionais para que tal ocorra, nomeadamente fatores associados aos locais de nidação das células (7).

\subsection{Identificação, isolamento e enriquecimento das CTCs}

Relativamente à tecnologia para identificação das CTCs, o primeiro grande desafio relaciona-se com o reduzido número de CTCs em circulação em relação aos restantes elementos celulares (8). Para o isolamento de CTCs, as abordagens típicas baseiam-se em características físicas ou na seleção de marcadores destas células. A deteção de CTCs pode ter como base o tamanho e outras propriedades biofísicas. Outra forma de deteção assenta na identificação baseada em marcadores tipicamente expressos na superfície dessas células, nomeadamente a molécula de adesão das células epiteliais (EpCAM), através de meios de enriquecimento (4).

Até à data, somente o sistema CellSearch ${ }^{\circledR}$ foi aprovado pela FDA (Food and Drugs Administration) para contagem de CTCs no cancro da próstata metastizado (9). O sistema CellSearch $^{\circledR}$ é a plataforma clinicamente mais estudada para a quantificação das CTCs. Este sistema isola as CTCs de origem epitelial através de técnicas imunomagnéticas, que têm como alvo a EpCAM, usando nanopartículas ferrofluídas ligadas a anticorpos dirigidos a essa molécula, por forma a conseguir separar as células EpCAM+ da camada leucoplaquetária do sangue centrifugado. Após a captura imunomagnética, são adicionados reagentes fluorescentes: um específico para as citoqueratinas das proteínas intracelulares características das células epiteliais (nomeadamente CK8, CK18 e CK19), um reagente que cora o núcleo das células mononucleares do sangue periférico, e ainda o antigénio específico dos leucócitos (anti-CD45), para seleção negativa destas células. Depois deste processo, que é totalmente automatizado, obtêm-se as potenciais CTCs, que são: EpCAM+, CK+, DAPI+ e CD45- (as CTCs são portanto definidas como células nucleadas desprovidas de CD45 e que 
expressam citoqueratinas). Estas são então analisadas e verificadas por um anatomopatologista $(3,7)$, já que adicionalmente, uma CTC tem que exibir certas características morfológicas específicas a ser identificadas por patologistas experientes (5).

Contudo, tem-se verificado alguma heterogeneidade das CTCs, podendo daí advir potenciais limitações na identificação dependente somente da EpCAM (7). Basicamente, a definição das CTCs como sendo EpCAM+, CK+, DAPI+ e CD45- corresponde a uma definição canónica, que efetivamente permite identificar as células epiteliais, mas não inclui toda a população de células tumorais em circulação, como é o caso das CTCS que não expressam EpCAM (células que sofreram uma transição epitélio-mesenquimatosa), bem como das células com diferenciação neuroendócrina, que também expressam baixos níveis de marcadores epiteliais. Estas células associam-se a um aumento da agressividade do tumor, capacidade de escape ao sistema imune e maior capacidade de nidação à distância. Portanto, o sistema CellSearch $^{\circledR}$ não oferece o crivo completo de todas as potenciais células tumorais em circulação no sangue (3), sendo que as CTCS que não expressam EpCAM não serão detetadas pelo teste, assim como as CTCs que expressam EpCAM mas que não expressam citoqueratinas 8, 18 e 19.

Sabe-se ainda que os tumores não libertam células totalmente intactas na corrente sanguínea, pelo menos até um estadio relativamente tardio da doença, pelo que em estadios mais precoces o número de CTCs em circulação é limitado, o que acaba por tornar esta abordagem mais limitada para aplicação clínica generalizada, sendo necessário desenvolver outros marcadores que permitam construir um painel que torne possível a sua aplicação clínica (4).

Outras plataformas alternativas ao sistema CellSearch ${ }^{\circledR}$ isolam as células independentemente dos antigénios que exibem na sua superfície, utilizando para isso características físicas como tamanho, deformabilidade e/ou propriedades isoelétricas (7).

A interpretação dos estudos clínicos deve ter em conta o método de enriquecimento e de identificação das CTCS, pois este detalhe afeta diretamente a população de células capturadas.

\subsection{Aplicações clínicas}

\subsubsection{Enumeração de CTCs}

A deteção de CTCs no cancro da próstata é estadio-dependente e a sua contagem tem sido avaliada sobretudo nos estadios avançados do cancro da próstata.

A contagem de CTCs tem valor prognóstico tanto no cancro da próstata metastizado sensível à castração (mCSPC) como no cancro da próstata resistente à castração (mCRPC), sendo expectável um número maior de CTCs no cancro da próstata metastizado, devido ao aumento do volume de doença em circulação. Em geral, considera-se que uma contagem de 5 ou mais CTCs em 7,5 mL de 
sangue em qualquer altura durante o curso da doença está associada a um pior prognóstico e é indicador de sobrevida livre de progressão e sobrevida global mais curtas.

Em relação ao mCSPC, em 2008, Okegawa mostrou que a identificação de 5 ou mais CTCs na contagem inicial era o valor que se associava a pior resposta à ADT, com os doentes que apresentavam contagens iniciais de $\geq 5$ CTCs a terem uma pior resposta à ADT (17 meses vs. 32 meses) (10). Portanto, o valor inicial de CTCs prediz a duração da resposta à terapia hormonal e a contagem de CTCs pode catalogar os doentes com maior risco de progressão para mCRPC antes do início da ADT.

Goldkorn, em 2016, corroborou que a presença de CTCs na contagem basal de doentes com mCSPC se associa a fatores de mau prognóstico, como PSA mais elevado, metástases ósseas, doença mais agressiva e tendência a um pior performance status (11).

Portanto, as CTCs têm a capacidade de predizer o tempo que demorará a ocorrer a resistência à castração, pelo que o seu uso na prática clínica poderá ser benéfico para identificar os doentes que potencialmente irão beneficiar de um tratamento mais precoce com quimioterapia (10-12). Já no estadio da doença resistente à castração, a capacidade de prognóstico das CTCs está bem estabelecido e a contagem das CTCS através do sistema CellSearch ${ }^{\circledR}$ já foi aprovada pela FDA como marcador de prognóstico. Foram os resultados do estudo de De Bono, em 2008 que conduziram a esta aprovação. Para além de terem sido identificadas CTCs em 95\% dos homens com doença metastizada na contagem inicial (demonstrando assim a prevalência de CTCs nos estádios avançados da doença), as contagens iniciais de CTCs consideradas desfavoráveis ( $\geq 5$ CTCs) foram associadas a menor sobrevida global (11,5 vs. 21,7 meses). Adicionalmente, os doentes com contagens iniciais de CTCs desfavoráveis que se converteram em contagens favoráveis ( $<5$ CTCS) após o início do tratamento, apresentaram melhorias similares na sobrevida mediana, demonstrando a capacidade das CTCS em refletir a resposta à terapêutica nestes doentes e concluindo-se que a quantificação das CTCS é a forma mais precisa de predizer a sobrevida global no mCRPC (9). Em 2016, Lorente também demonstrou que uma diminuição de $30 \%$ da contagem de CTCs de doentes com mCRPC nas 4 semanas após o tratamento se associa a melhor sobrevida global (13).

A eficácia prognóstica das CTCs foi estudada no contexto de vários tratamentos sistémicos para o cancro da próstata avançado (incluindo o docetaxel, abiraterona e combinações de fármacos), demonstrando-se consistentemente uma associação com a sobrevida global $(14,15)$.

Em suma, no que diz respeito à quantificação das CTCs, o número de CTCs presentes no sangue periférico parece estar correlacionado com a evolução da doença. A deteção de $\geq 5$ CTCs em $7,5 \mathrm{~mL}$ de sangue usando o sistema CellSearch $^{\circledR}$ foi validado como um marcador de prognóstico em doentes com cancro da próstata metastizado, sendo a contagem inicial de CTCs prognóstica 
da sua sobrevida global. Para além disso, um aumento da contagem de CTCs em qualquer momento durante a terapêutica está associado a uma redução da sobrevida global, especialmente se esse aumento acontecer precocemente. Já uma diminuição da contagem de CTCs num doente sob terapêutica sugere melhor prognóstico. Portanto, existe uma forte associação entre a evolução da doença e a contagem de CTCs, especialmente se esta for usada como uma variável contínua. Assim sendo, a quantificação de CTCS pode ser usada no follow-up dos doentes com cancro da próstata metastizado, com benefício prognóstico e preditivo $(5,9-15)$.

\subsubsection{Identificação de fenótipos e caracterização das CTCs:}

Enquanto os primeiros estudos se focaram na contagem das CTCs, os trabalhos subsequentes concentraram-se na caracterização genética ou do perfil proteico das células obtidas. A caracterização das células permite esclarecer aspetos dos perfis moleculares dos doentes individualmente e guiar as escolhas de tratamento.

\section{- Recetor dos androgénios:}

Embora existam muitos potenciais alvos para a caracterização das CTCs, a maioria dos estudos clínicos têm-se focado no recetor dos androgénios (AR), dado o seu papel central na terapêutica do cancro de próstata avançado (7). A sinalização persistente do AR, apesar da ADT, é um dos principais determinantes da progressão da doença, nomeadamente da resistência à castração. Consequentemente, o AR tem sido estudado nas CTCs como um potencial biomarcador na doença em estadio avançado.

O perfil genómico do AR nas CTCs contém muitas das mesmas mutações genéticas que já haviam sido implicadas na progressão da doença a partir de estudos de autópsia, incluindo a identificação de amplificações do gene AR $(16,17)$, e assim sendo, as CTCs poderão ter utilidade para a monitorização seriada de mutações no AR recentemente adquiridas como mecanismo de resistência ao tratamento.

A coloração por imunofluorescência do AR nas CTCs para determinar a localização celular (nuclear vs. citoplasmática) tem sido associada à resposta quimioterápica e à progressão clínica da doença nos doentes sob abiraterona. Portanto, para além do perfil genómico, o fenótipo do AR também foi investigado nas CTCs. Os doentes com mCRPC nos quais o AR das CTC está retido predominantemente no citoplasma, em vez de se localizar no núcleo, apresentam uma resposta significativamente melhor à quimioterapia com docetaxel, pelo que a monitorização da localização do AR nas CTCs em doentes com mCRPC pode constituir um preditor clínico de resposta aos taxanos (18). 
Mais recentemente identificaram-se isoformas do recetor dos androgénios, que são variantes do $A R$ independentes de ligandos que desempenham um papel importante na resistência às terapias anti-androgénicas de segunda geração - a enzalutamida e a abiraterona (19). De facto, a presença de qualquer variante do AR associa-se a pior prognóstico, sendo que qualquer alteração no recetor dos androgénios tem influência na resposta aos tratamentos instituídos (20).

Já foram descritas cerca de 15 variantes diferentes, sendo que as que se considera clinicamente mais relevantes são as AR-V7, AR-V9 e AR-V567, com os estudos mais recentes com CTCs a concentrarem-se na variante 7 do recetor dos androgénios (AR-V7), que é uma variante do $A R$ constitutivamente ativa, com uma região terminal truncada e sem o domínio de ligação ao ligando, permitindo que a sinalização do recetor dos androgénios seja ativada independentemente de um ligando. Isto faz com que ocorra uma expressão autónoma da proteína da variante do AR. A sobreexpressão de um recetor constitutivamente ativo mas que não tem o domínio de ligação ao ligando (que é um local de ligação para algumas drogas antiandrogénicas) confere resistência ao tratamento anti-androgénico (4).

Antonarakis (2014, 2015 e 2017), procedeu à deteção do transcrito AR-V7 em CTCs enriquecidas com EpCAM de homens com mCRPC. Nos doentes com AR-V7 não detetável nas CTCs observou-se resposta tanto à enzalutamida como à abiraterona, determinada pela redução sérica dos níveis de PSA em $\geq 50 \%$. Já nos homens com expressão do AR-V7 observaram-se taxas de resposta do PSA, sobrevida livre de progressão e sobrevida global significativamente menores quando tratados com enzalutamida ou abiraterona, sugerindo um possível meio de prever a resposta a essas terapias através do perfil das CTCs. Portanto, a deteção do AR-V7 foi associada a resistência à enzalutamida e à abiraterona (19) (mas não ao docetaxel ou ao cabazitaxel (21)). A presença de CTCs positivas para o AR-V7 associa-se a pior evolução clínica em comparação com a presença de CTCs negativas para o AR-V7, mas que ainda assim é pior do que não ter CTCs. Portanto, a expressão de CTCS baseada no AR-V7 parece constituir um potencial biomarcador preditivo associado à resistência à abiraterona e à enzalutamida, favorecendo a escolha dos taxanos como arma terapêutica (22), já que a resposta ao tratamento com estes fármacos é independente do status do AR-V7 nas CTCs, sendo uma opção válida para os doentes AR-V7 positivos (23).

Em conclusão, o papel da AR-V7 como biomarcador de resposta ao tratamento não se limita apenas aos inibidores da sinalização do AR. Sabe-se que os taxanos funcionam como estabilizadores de microtúbulos e induzem o controlo mitótico. Podem ainda funcionar no cancro da próstata pela prevenção da translocação dependente dos microtúbulos do AR para o núcleo das células. Nos homens positivos para o AR-V7, os taxanos parecem ser mais eficazes do que a terapia com enzalutamida ou abiraterona, enquanto nos homens negativos para o AR-V7, os taxanos e a enzalutamida ou a abiraterona podem ter eficácia comparável. 
O AR-V7 é um marcador dinâmico e a sua análise repetida pode ser capaz de capturar transições no seu status, como resultado dos diferentes tratamentos. As conversões de AR-V7 negativo para positivo ocorrem mais comummente em doentes sob terapêutica dirigida ao $A R$, enquanto que reversões inversas (de AR-V7 positivo para negativo) parece ocorrer apenas com quimioterapia baseada em taxanos. Análises sequenciais de CTCs podem fornecer informações mais detalhadas relativamente à evolução da doença, sendo ainda necessários estudos de follow-up que possam determinar a sua relevância clínica (4).

\section{- Fenótipo epitélio-mesenquimatoso e neuroendócrino:}

A transição epitélio-mesenquimatosa ocorre por quebra de adesão da matriz celular. A E-caderina é um dos principais componentes da junção de adesão epitelial e atua como o principal guardião da transição, pelo que a sua perda, é considerada o gatilho para que a transição ocorra.

O fenótipo mesenquimatoso e o fenótipo neuroendócrino no cancro da próstata em estadio avançado associam-se a doença mais agressiva. Segundo McDaniel (2017), o grau de heterogeneidade fenotípica é caracterizado por uma multiplicidade de subtipos de CTCs não canónicos, como células CK-negativas, CTCs pequenas e agregados independentes de CTCs. As populações de CTCs ditas de não tradicionais parecem ser mais frequentes no mCRPC e a sua caracterização pode fornecer informações prognósticas ou preditivas adicionais (24). Numa coorte de doentes em estadio avançado descrita por Scher em 2017, a baixa heterogeneidade de CTCs foi associada a melhor sobrevida com terapia anti-androgénica de segunda linha, enquanto uma alta heterogeneidade se associou a melhor sobrevida nos doentes sob quimioterapia com taxano, pelo que a heterogeneidade individual de cada tumor pode estar associada a resistência aos tratamentos e a descrição da heterogenidade fenotípica das CTCs pode auxiliar na escolha da terapêutica (25).

\section{- Presença do gene de fusão TMPRSS2-ERG:}

Outra alteração associada ao cancro da próstata que foi identificada nas CTCs de doentes com doença avançada são os rearranjos do oncogene ERG. A expressão androgénica do oncogene ERG após a fusão com a protease transmembranar serina2 (TMPRSS2), ocorre em 30-70\% dos cancros de próstata terapeuticamente naïve. Está descrita uma associação do status do ERG com a magnitude da resposta do PSA (26), e os doentes positivos para a fusão TMPRSS2-ERG têm uma sobrevida livre de progressão radiográfica e uma resposta do PSA significativamente piores (27). Apesar de não ser possível tirar uma conclusão clara sobre o valor da avaliação dos rearranjos ERG nas CTCs como um biomarcador preditivo, o seu estudo é tido como promissor. 
- Perda do PTEN:

Outra alteração identificada está relacionada com a perda do gene supressor tumoral homólogo da fosfatase e da tensina (PTEN), que ocorre frequentemente no mCRPC e tem sido associada à progressão do mesmo. A perda do PTEN associa-se frequentemente a rearranjos ERG. Existe uma concordância entre o status do PTEN nos tecidos e as CTCs e a análise do PTEN nas CTCs parece ser representativa do status do PTEN no tecido metastático, podendo desta forma assumir importância clínica. Punnoose, em 2015 demonstrou que quando há perda do PTEN nas CTCs há concordância com o status do PTEN no tecido tumoral biopsado, analisando o status do PTEN em doentes com mCRPC e observando uma correlação entre este e a sobrevida, com a perda do PTEN nas CTCS a ser associada a pior prognóstico (28). Assim como para os rearranjos ERG, o valor da perda do PTEN nas CTCs como potencial biomarcador ainda está pouco estudado, podendo vir a ter importância futura.

\section{- Atividade da telomerase:}

A telomerase está associada ao envelhecimento celular. Nas células somáticas, esta enzima encontra-se naturalmente reprimida, o que resulta na morte celular. A sua ativação conduz à imortalização celular, que é uma característica das células malignas. O aumento da atividade da telomerase resulta numa replicação celular mais eficaz e, de facto, os doentes com elevadas contagens de CTCs $(\geq 5)$, que associadamente têm uma atividade elevada da telomerase apresentam uma menor sobrevida global $(29,30)$. O estudo da telomerase é descrito como promissor no cancro da próstata.

Concluindo, do ponto de vista clínico, a aplicação das CTCs como biomarcadores de prognóstico e de predição parece ainda estar limitada à capacidade de detetar essas mesmas células, que em muito depende do estadio de progressão do cancro da próstata. Doentes em estadios precoces da doença têm uma baixa frequência de deteção das CTCS, e enquanto as taxas de deteção das CTCS no sangue forem extremamente baixas na doença não mestatizada, a biópsia líquida tem um valor limitado nesses estadios. Num futuro próximo é mais provável que o perfil molecular baseado em CTCs tenha impacto na monitorização de estadios avançados da doença (4). 


\section{Material Genético Livre}

O material genético livre inclui DNA e RNA, designadamente, DNA livre circulante (cfDNA) e micro RNAs (miRNA), que circulam livremente na corrente sanguínea.

\subsection{DNA livre circulante - cfDNA}

A designação DNA livre circulante inclui o cfDNA total do doente e o DNA específico do tumor (cftDNA).

O cfDNA refere-se a todos os fragmentos de DNA que circulam livremente e que são libertados para a corrente sanguínea por todas as células - malignas e não malignas. O DNA livre específico do tumor em circulação, designado por cftDNA (circulating free tumor DNA) refere-se aos fragmentos de DNA que circulam livremente na corrente sanguínea e que derivaram especificamente de células tumorais, contendo as mesmas alterações genéticas do local de origem. O mecanismo pelo qual os fragmentos de material genético são libertados são desconhecidos, mas genericamente é aceite que os fragmentos de DNA específicos do tumor em circulação podem ter origem no tumor primário, em qualquer lesão metastática ou até nas CTCs. Estes fragmentos são libertados de forma ativa ou através de mecanismos de apoptose/necrose celular (3) e o isolamento das pequenas frações de cftDNA no total de cfDNA exige uma abordagem muito sensível no sentido de se identificarem alterações genéticas específicas, anomalias cromossómicas, alterações epigenéticas ou outras características que permitam afirmar a sua origem tumoral (7). Uma vez detetado, o cftDNA reflete o perfil genético do tumor "contemporâneo", já que os ácidos nucleicos livres em circulação têm uma semivida muito curta (2).

No contexto do cancro da próstata existem evidências que a análise do cfDNA/cftDNA tem potencial para futuras aplicações clínicas, constituindo uma ferramenta para avaliação não invasiva do tumor, que não exige equipamento específico (ao contrário das CTCs) (31).

As aplicações do cfDNA no diagnóstico, prognóstico e como preditor de recorrência e de resposta ao tratamento no cancro da próstata estão descritas na Tabela I.

\subsubsection{Aplicações clínicas}

A análise do cfDNA pode ser quantitativa e qualitativa.

\section{- Análise quantitativa:}

No que diz respeito à quantificação, apesar de quantidades maiores de cfDNA não serem literalmente diagnósticas, os doentes com cancro da próstata têm um nível mais elevado em circulação, quando comparados com indivíduos saudáveis (32), cujo cfDNA deriva sobretudo de 
hematopoiese com uma concentração sérica média de $99 \mathrm{ng} / \mathrm{mL}$ de sangue. Já nos doentes com cancro da próstata, a concentração sérica de cftDNA é de cerca de $437 \mathrm{ng} / \mathrm{mL}(31,32)$.

A quantificação do cftDNA, especialmente no contexto da sua evolução ao longo do tempo, consiste num meio para avaliar a carga tumoral e a resposta à terapêutica. Os doentes com cancro da próstata metastizado que apresentem uma maior fração de cftDNA têm uma maior carga de doença e um pior prognóstico (33), sendo que doentes com menores níveis de cftDNA respondem melhor à terapêutica $(33,34)$.

A quantidade absoluta de cftDNA e sua proporção relativamente ao cfDNA total (cftDNA/cfDNA) pode ser usada como um biomarcador, como evidenciado no estudo de Romanel (2015), em que a deteção de quantidades crescentes de cftDNA mostrou correlacionar-se com outros marcadores globais de carga tumoral (nomeadamente, com a fosfatase alcalina e LDH) e com uma evolução clínica significativamente pior (33).

Kienel (2015), num estudo em que analisou a valor prognóstico da concentração de cfDNA em homens com mCRPC, verificou que uma concentração elevada se associou a uma má resposta do PSA, podendo ser usada como um preditor independente de sobrevida global (35). Da mesma forma que Kwee (2012) analisou os níveis de cfDNA em homens com mCRPC sob quimioterapia e demonstrou uma relação positiva entre os níveis de cfDNA e a progressão imagiológica (36).

\section{- Análise qualitativa:}

A análise qualitativa do cfDNA baseia-se na pesquisa de anomalias genómicas, incluindo alterações e mutações de metilação de um único gene, integridade do DNA (ou falta dela) e perda de heterozigotia de genes supressores tumorais.

Podem-se definir duas estratégias para a avaliação genómica: uma em que se procura um alvo específico com o objetivo de se detetar mutações concretas num gene de interesse; e outra em que se faz o sequenciamento completo do material genético (31).

A concordância entre o cftDNA e o tecido tumoral foi descrita por Wyatt, em 2018, após a obtenção de biópsias líquidas e de biópsias de locais metastáticos (viscerais, ósseos e nódulos linfáticos). As amostras de cftDNA obtidas na biópsia líquida continham todas as alterações do DNA, em frequências alélicas semelhantes, encontradas no sequenciamento genómico completo das lesões metastáticas biopsadas, incluindo alterações como a mutação e amplificação do gene dos recetores dos androgénios (gene $A R$ ), mutação no gene SPOP, inativação de genes supressores tumorais como o BRCA2, TP53, PTEN, RB1, APC, CDKN1B e PIK3R1 (37). Para além destes também os genes BRCA1 (38, 39), ATM, CHEK2, RAD51D, PALB2 (39), TMPRSS2-ERG (40, 41), RYBP, SHQ1 (41), MYC (41, 42), BRAF, NF1, EGFR, CTNNB1, ARID1A (42) estão implicados na patogénese do cancro da próstata metastizado, com potencial significado clínico prognóstico. As 
frequências destas mutações nos doentes com cancro metastizado estão apresentadas na Tabela II.

A presença de alterações no cftDNA é extremamente frequente nos doentes com mCRPC,: Sonpavde (2019) detetou $\geq 1$ alterações no cftDNA em $94 \%$ dos doentes com mCRPC, sendo que a acumulação de alterações no cttDNA, as amplificações dos genes MYC e BRAF e as alterações no gene AR associaram-se a pior sobrevida global (42). Já Wyatt (2016) também tinha encontrado mutações ou alterações no número de cópias de genes em todos os doentes com mCRPC da sua coorte aquando da progressão da doença (34).

Tendo-se o conhecimento dos genes que estão potencialmente mutados, e sabendo-se que existe concordância entre o cftDNA e as biópsias tumorais, é possível desenhar estudos em que se pesquisem essas mutações no cftDNA e as repostas aos tratamentos.

\section{- Gene AR:}

Da mesma forma que nas CTCs, o recetor dos androgénios representa um alvo importante no contexto da análise do cfDNA, devido ao seu papel no tratamento. A identificação da amplificação do gene AR, assim como certas mutações nesse gene em específico têm sido estudados como biomarcadores de resistência à terapêutica antiandrogénica.

No caso do cancro da próstata metastático, os estudos de Carreira (2014), Salvi (2015), Romanel (2015) e Conteduca (2017) focaram-se nas alterações genómicas do gene AR antes e após o tratamento com abiraterona. Nas amostras obtidas antes de se iniciar o tratamento, um maior número de cópias do gene AR ou mutações pontuais foram identificadas em até $45 \%$ dos doentes, sendo que a sua presença se associa a menor sobrevida livre de progressão e menor sobrevida global $(33,43-45)$. Salvi (2015) avaliou o cfDNA de doentes com mCRPC antes do início do tratamento com abiraterona e encontrou uma associação significativa entre os ganhos no número de cópias do gene AR (e também do gene CYP17A1) e uma menor sobrevida global e menor tempo de sobrevida livre de progressão (45). Já Carreira (2014) demonstrou uma associação temporal entre a progressão clínica e a emergência de mutações no gene AR, ativadas em doentes sob abiraterona (43). Romanel (2015) identificou duas mutações pontuais do gene AR associadas à resistência à abiraterona (concretamente T878A e L702H). Este estudo avaliou simultaneamente o número de cópias e as mutações somáticas pontuais no cfDNA das regiões codificadoras do AR do plasma de doentes com mCRPC imediatamente antes de iniciar a abiraterona, durante o tratamento e após a progressão. Os doentes com ganho do número de cópias do gene AR ou com as mutações pontuais específicas tiveram um menor declínio dos níveis de PSA, menor sobrevida livre de progressão e menor sobrevida global. Além disso, o 
aparecimento de novas mutações pontuais no gene AR foi identificado em $13 \%$ dos doentes que progrediram estando sob abiraterona (33).

Nos estudos com enzalutamida os achados foram idênticos: no estudo de Lallous (2016), a presença de alterações no gene AR (mutações e alterações do número de cópias) associou-se a sobrevida livre de progressão e sobrevida global mais curtas, comparativamente aos doentes com AR normal (46). Azad, em 2015, analisou o número de cópias e o sequenciamento do exão 8 do gene AR no cfDNA mostrando que a sua amplificação estava ligada à resistência à enzalutamida. Isto prende-se com o facto do exão 8 codificar uma parte de um domínio de ligação ao ligando que é o alvo da terapêutica com a enzalutamida. Desta forma, a existência de uma mutação nesta localização específica conduz mais provavelmente a uma resistência a este fármaco. Para além disso, a amplificação do gene AR foi descrita como sendo muito mais comum nos doentes com progressão da doença sob enzalutamida, comparativamente com os doentes sob abiraterona ou outros tratamentos, nomeadamente taxanos. A presença de alterações do gene AR no cftDNA obtido previamente ao tratamento foi preditiva de menor taxa de declínio do PSA e menor tempo até a progressão (47).

Já Conteduca, em 2017, demonstrou que a identificação de amplificações do gene AR e também das mutações pontuais específicas em doentes com mCRPC faz prever um pior desfecho se tratados com abiraterona ou com enzalutamida, quando comparados com o tratamento com taxanos, pelo que concluiu que a avaliação do status do gene AR antes do início do tratamento pode vir a ser útil na previsão da resposta à terapia a instituir (44).

Também a variante AR-V7 já foi identificada no sangue periférico de doentes com cancro metastizado, sendo que a sua expressão em níveis elevados se associa a não resposta do PSA, menor sobrevida livre de progressão e sobrevida global mais curta destes doentes (48).

De Leare (2017) detalhou o perfil do gene AR do cftDNA de homens com mCRPC avaliando qualquer alteração do $A R$, estabelecendo uma associação entre a presença de qualquer variante AR e a sobrevida livre de progressão. No caso dos doentes que eram AR-V7 negativos, mas que tinham resposta fraca ao tratamento, encontraram-se outras anomalias do gene AR (20).

Resumidamente, as amplificações e mutações do gene AR correlacionam-se com prognóstico. 0 aparecimento, num dado momento, de novas alterações genómicas pode servir como um sinal de progressão da doença, ao mesmo tempo em que aponta para novos mecanismos de resistência que podem ser direcionados terapeuticamente. Portanto, no contexto da biópsia líquida, o cftDNA é especialmente útil para a análise seriada ao longo do curso da doença.

\section{- Mutações noutros genes:}

Existem outros estudos que se têm focado na linha germinativa e nos defeitos somáticos adquiridos na reparação do DNA envolvendo genes como o BRCA1 e 2, ATM e o PALB2 $(39,49)$. A 
presença de mutações germinativas nesses genes foi associada a um risco significativamente aumentado de cancro de próstata metastático, doença mais agressiva e pior resposta à terapêutica dirigida ao AR (39), sendo que mutações somáticas adquiridas também são observadas em frequências muito mais altas nos tumores que progridem para $\operatorname{mCRPC}(49,50)$.

No estudo de Annala (2017), os doentes com mCRPC portadores de mutações germinativas BRCA2 apresentaram progressão significativamente pior e menor tempo de sobrevida livre de progressão quando tratados com abiraterona ou enzalutamida, comparativamente aos doentes sob docetaxel (51). Por outro lado, os doentes com alterações nos genes de reparação do DNA parecem responder à quimioterapia ou ao inibidor da polimerase PARP. Estudos com o inibidor da PARP, o olaparib, mostram que este é mais eficaz em doentes com mutações nos genes de reparação do DNA detetados em biópsias, especialmente no caso de mutações BRCA (38). A importância clínica deste mecanismo foi primeiramente descrita por Fong em 2009 que demonstrou a eficácia terapêutica do olaparib em doentes portadores de mutações germinativas no gene BRCA (52). Num estudo subsequente de Mateo (2015), 33\% dos doentes apresentaram defeitos em genes de reparação do DNA, e o olaparib induziu uma resposta em $88 \%$ desses doentes (38). Já Goodgall, em 2017, descreveu que uma redução $\geq 50 \%$ do cfDNA foi associada a melhor sobrevida global e a sobrevida livre de progressão radiográfica nas 8 semanas após o tratamento com olaparib (53).

Estes achados mostram a necessidade de se estabelecerem estratégias de tratamento guiadas por biomarcadores no cancro da próstata avançado, sugerindo que a análise do cfDNA pode ser usada para auxiliar na decisão mais precoce de se optar pela quimioterapia ou pela inibição da PARP (com olaparib).

Resumindo, as aplicações do cfDNA têm probabilidade de ter impacto em estadios avançados de resistência à castração do que para fins de diagnóstico ou de rastreio da doença em estadio inicial. O desenvolvimento de um conjunto de marcadores à base de cftDNA para serem aplicados na fase avançada da doença podem servir como preditores de progressão e de resposta à terapêutica.

\subsection{RNA}

Lee, em 1993, identificou o "lin-4", que foi o primeiro microRNA descrito (54). Atualmente já existem 38589 microRNAs registados na base de dados miRBase (miRBase v22.1 Outubro 2018) (55).

Os miRNAs são pequenos segmentos de 18 a 22 nucleotídeos não codificantes, com função reguladora, modulando a expressão de cerca de $30 \%$ dos genes que codificam proteínas, sendo 
que um único miRNA é capaz de regular centenas de genes diferentes. Quando ocorre uma modificação na expressão de um miRNA um conjunto de processos biológicos pode ser afetado, podendo constituir o gatilho para a tumorogénese e/ou afetar a progressão da doença (31).

No caso do cancro, a importância dos miRNAs relaciona-se com o facto destes se localizarem em regiões genómicas "frágeis" que estão muitas vezes alteradas nos tumores (56). A expressão de miRNAs forma uma espécie de assinatura, composta por um conjunto de miRNAs sobrexpressos/subexpressos, que é capaz de identificar o tipo de cancro em causa (57).

Os miRNAs associados ao cancro podem ser detetados a circular livremente no sangue periférico de doentes com cancro de próstata e, nesse sentido são vistos como potenciais biomarcadores prognósticos ou preditivos, com especial interesse no cancro de próstata avançado.

O papel dos miRNAs na oncogénese relaciona-se com o facto destes serem capazes de inibir genes supressores tumorais (por exemplo o PTEN) ou por outro lado estimular oncogenes (por exemplo o MYC e o RAS) (58-62).

Existem miRNAs específicos que se parecem correlacionar com o cancro da próstata, com o prognóstico dos doentes com mCRPC e com a quimiorresistência, nomeadamente, o miR-15, miR16, miR-21, miR-141, miR-221, miR-200 (58, 63-66). A sua expressão e o respetivo efeito dessa expressão estão descritos na Tabela III.

Estão também descritas algumas assinaturas de miRNAs, nomeadamente relacionadas com o diagnóstico, prognóstico e predição de resposta à terapêutica. Essas assinaturas estão identificadas na Tabela IV.

\subsubsection{Aplicações clínicas:}

Vários miRNAs foram associados ao diagnóstico e ao prognóstico do cancro da próstata. Relativamente ao diagnóstico (e nesse caso, os miRNAs terão interesse nos estádios precoces do cancro da próstata), a identificação de alterações na regulação dos miRNAs let-7a, miR-15, miR16, miR-21, miR-24, miR-93, miR-106a, miR-130b, miR-141, miR-221, miR-223, miR-375 e miR-451 pode permitir diferenciar indivíduos com cancro da próstata de indivíduos saudáveis (ou com doença benigna) $(58,63,67-71)$. Por exemplo, a expressão do miR-15 e do miR-16 séricos está diminuída no caso do cancro da próstata (quando comparado com indivíduos saudáveis, doentes com prostatite crónica e hiperplasia benigna da próstata) (58).

Para além dos miRNAs isoladamente, também já foram descritas assinaturas de miRNAs associadas ao diagnóstico do cancro da próstata. Por exemplo: o painel miR-24, miR-223, miR-93, miR-106a, miR-451 (69), o painel miR-141, pelo miR-21 e miR-375 (68) e também o painel constituído pelo miR-96, miR-183, miR-145 e pelo miR-221 permitem a distinção entre doentes com cancro da próstata de controlos saudáveis (72). 
No caso do miR-141, a sua sobrexpressão já foi amplamente associada ao cancro da próstata: está sobrexpresso nos doentes com cancro da próstata (vs. doentes saudáveis ou com doença benigna) $(63,67,68)$, com sobrexpressão mais marcada no mCRPC (vs. cancro da próstata localizado) (73), com níveis ainda mais elevados a correlacionarem-se com doença metastática mais extensa (74).

De forma similar, Agaoglu, em 2011, para além de quantificar níveis mais elevados de miR-141, miR-21 e miR-221 em doentes com cancro da próstata (relativamente aos indivíduos saudáveis), no caso específico dos doentes com cancro da próstata metastizado, os níveis dos três miRNAs estavam significativamente mais elevados relativamente aos doentes com doença localizada ou localmente avançada (63). Shen, em 2012, obteve resultados semelhantes, com os níveis de miR21 no plasma a estarem sobrexpressos nos doentes em estadios mais avançados. Estes resultados sugerem que alterações nos níveis de miRNAs plasmáticos podem permitir estratificar a agressividade do tumor (64). Por exemplo, está descrito que um painel que demonstre a perda do miR-15 e do miR-16 e a sobrexpressão do miR-21 representa uma assinatura promissora no que concerne à predição de um pior prognóstico no cancro da próstata (60), já que miR-15 e o miR-16 são microRNAs supressores tumorais, cuja expressão está diminuída nos doentes com cancro da próstata (vs. controlos saudáveis, doentes com prostatite crónica e HBP) e níveis muito baixos ou inexistentes associam-se a estadios metastáticos (58). Já o miR-21 é um onco-miRNA, que promove a proliferação celular, invasão e diminuição da apoptose, cuja sobrexpressão se associa a progressão da doença (63).

\section{- microRNAs e predição de resposta à terapêutica:}

Existem alguns microRNAs estudados no contexto da resposta ao tratamento em doentes com mCRPC.

Lin, em 2014, identificou 14 miRNAs associados à resposta do PSA sérico ou à sobrevida global em doentes com mCRPC sob docetaxel. Os doentes que não responderam ao docetaxel e os doentes com sobrevida mais curta tinham níveis de microRNAs da família miR-200 (miR-200a, miR-200b, miR-200c, miR-429) mais elevados antes do início do tratamento com docetaxel (ou níveis diminuídos/inalterados de microRNAs da família miR-17 (miR-20a) após o tratamento). Portanto, a deteção de níveis elevados de miRNAs da família miR-200 parece ser preditiva de não resposta ao docetaxel e consequentemente de menor sobrevida (66).

Também Zhang, em 2010, identificou o miR-21 (onco-miRNA) sobrexpresso nos doentes com mCRPC, sendo que a expressão de níveis mais elevados se associou a quimiorresistência ao docetaxel (65). 
Portanto, a identificação de miRNAs preditores de quimiorresistência pode permitir orientar individualmente as decisões terapêuticas.

Em resumo, a identificação de miRNAs, isoladamente ou em conjunto (formando assinaturas) permitirá, no futuro, criar painéis de biomarcadores com potencial diagnóstico, prognóstico e preditivo de resposta às terapêuticas, auxiliando na tomada de decisão em oncologia prostática. Para além de se considerar os miRNAs como potenciais preditores de evolução da doença e de resposta ao tratamento, a descoberta de microRNAs "oncogénicos" e "supressores tumorais", assim como a capacidade de manipular os seus níveis utilizando oligonucleotídeos que mimetizam ou inibem a sua função conduziram ao desenvolvimento de miRNAs com potencial terapêutico, já que se pode usar um único microRNA para silenciar múltiplos genes ou vias de sinalização simultaneamente envolvidos na resistência às terapêuticas $(75,76)$.

Apesar destas evidências, o papel dos miRNAs na predição da evolução da doença e da resposta à terapia, assim como a terapêutica baseada em microRNAs ainda está em fases precoces de estudo e embora estes resultados iniciais pareçam promissores, é necessária uma validação adicional antes das aplicações clínicas.

\section{Vesículas extracelulares}

As vesículas extracelulares (EVs) são uma classe heterogénea de partículas que têm um tamanho que varia de $50 \mathrm{~nm}$ a $10 \mu \mathrm{m}$ e que são liberadas por qualquer célula quer fisiologicamente quer patologicamente (77). O seu conteúdo parece ser muito específico, transportando RNA, proteínas e metabolitos e a sua função é partilhar essa informação molecular entre células, podendo dessa forma modificar a atividade da célula recetora (78).

Como as EVs estão em circulação e refletem a composição da célula de origem, elas constituem uma fonte de biomarcadores. O seu conteúdo está protegido da degradação por uma bicamada lipídica. No caso dos doentes com cancro, há um aumento do número de EVs circulantes, cujo conteúdo representa o local de origem, pelo que a sua análise pode fornecer informação acerca do tumor (77).

As vesículas extracelulares são subdivididas em exossomas, ectossomas e oncossomas. Os exossomas foram descritos pela primeira vez por Pan e Johnstone em 1983(79) e são um subtipo de EV com 50 a $100 \mathrm{~nm}$ de diâmetro com origem na fusão de corpos multivesiculares com a membrana plasmática. Os ectossomas e os oncosomas (1-10 $\mu \mathrm{m})$ originam-se diretamente na membrana plasmática das células (80). Os exossomas podem ter origem em células benignas e 
malignas. Os oncosomas, que são vesículas maiores, originam-se preferencialmente de células malignas (77).

As EVs provenientes do cancro da próstata podem detetar-se em circulação no plasma sanguíneo, na urina e/ou no líquido seminal (77).

\subsection{Aplicações clínicas}

\section{- Diagnóstico:}

Os doentes com cancro da próstata apresentam níveis elevados de exossomas plasmáticos que expressam simultaneamente CD81 e PSA (relativamente a indivíduos saudáveis e doentes com hiperplasia benigna da próstata) (81). Também a expressão genética de exossomas urinários (nomeadamente do ERG, PCA3 e SPDEF) permite diferenciar tumores com score de Gleason elevado de tumores de baixo grau e de doença benigna, pelo que a sua análise em homens com PSA elevado poderá, potencialmente, reduzir o número de biópsias desnecessárias (82).

Foi também demonstrada a presença da proteína PTEN nos exossomas de doentes com cancro (o que não se verifica nos exossomas de indivíduos saudáveis). Como o PTEN é uma proteína supressora tumoral (cuja expressão está reduzida no cancro da próstata), foi sugerida a teoria de que a existência de PTEN exossomal tem como objetivo compensar a perda do PTEN nas células alvo desses exossomas (83).

\section{- Desenvolvimento e progressão da doença:}

Os exossomas estão diretamente envolvidos na carcinogénese e na metastização do cancro da próstata, ao transportarem proteínas e material genético que reduzem a capacidade apoptótica, aumentam a proliferação celular e induzem a migração celular. Para além disso, são capazes de afetar a fusão e diferenciação osteoclástica, favorecendo a formação de nichos metastáticos (84). Alguns miRNAs exossomais estão descritos como estando implicados no desenvolvimento e progressão do cancro da próstata, nomeadamente o miR-100, miR-21, miR-139, miR-375, miR1290 e o miR-1246 exossomais $(85,86)$. Portanto, os miRNAs contidos nos exossomas circulantes também podem constituir biomarcadores prognósticos. Huang (2015) procedeu ao sequenciamento do RNA exossómico em homens com mCRPC, sendo que níveis mais elevados de miR-1290 e miR-375 se associaram de forma significativa a pior sobrevida global, independentemente da terapia, sugerindo uma potencial aplicação para a análise de exossomas (86).

Também Bhagirath (2018), correlacionou a sobrexpressão do miR-1246 exossomal com o grau patológico, a presença de metástases, pior prognóstico e maior agressividade do tumor (87). 
Portanto, os miRNAs podem ser encontrados na forma circulante, mas também incorporada em vesículas extracelulares. Com o objetivo de perceber se as EVs contêm quantidades biologicamente significativas de miRNAs e se podem fornecer uma melhor fonte de miRNA do que o plasma total, Endzelins (2017) comparou o potencial diagnóstico de miRNAs associados ao cancro da próstata no plasma e nas EVs. No entanto, os perfis dos miRNA livres circulantes e os miRNAs exossomais foram diferentes. O miR-375 foi capaz de diferenciar os doentes com cancro da próstata e hipertrofia benigna da próstata quando analisados no plasma, enquanto que o miR200 e o miR-21 tiveram melhor desempenho quando analisados em EVs, sugerindo que para alguns biomarcadores as EVs fornecem uma fonte de miRNA mais consistente do que o plasma total, enquanto que outros miRNAs apresentam melhor desempenho diagnóstico quando testados em todo o plasma (88).

\section{- Resistência às terapêuticas:}

As EVs também parecem ter um papel no desenvolvimento de resistência às terapêuticas em doentes com cancro da próstata, podendo dessa forma ser usadas como potenciais biomarcadores de resistência.

Kharaziha (2015) identificou alterações na quantidade de exossomas após resistência à quimioterapia, sugerindo que a monitoração quantitativa dos exossomas pode auxiliar na identificação da resistência aos taxanos (89).

No caso específico do AR-V7, o RNA mensageiro (mRNA) exossomal pode constituir uma fonte alternativa para a sua análise, através do seu transcrito. Del Re (2017) isolou RNA de exossomas provenientes do plasma de doentes com mCRPC e avaliou a presença do AR-V7, antes do início da terapia com abiraterona ou enzalutamida. $39 \%$ dos doentes eram AR-V7 positivos, e tiveram uma sobrevida livre de progressão e uma sobrevida global significativamente menores, comparativamente com os doentes AR-V7 negativos. Os resultados demonstraram que o RNA exossómico é uma fonte do status do AR-V7, corroborando também que a resistência à terapia hormonal pode ser prevista pelo AR-V7, considerando-a um biomarcador clinicamente relevante, seja identificado nas CTCs, no cfDNA ou no RNA exossomal (90).

A evolução contínua na deteção e análise diferencial das EVs permitirá caracterizar melhor o seu papel na sinalização do cancro da próstata, com as devidas implicações no prognóstico, predição de resposta à terapêutica e aplicação clínica. 


\section{Conclusão}

Numa perspetiva geral, a biópsia líquida (quando comparada com a biópsia tecidular) tem como vantagens o grau mínimo de invasividade para o doente, incrementando a frequência de monitorização, com maior representatividade da heterogeneidade tumoral contemporânea. Perante estas evidências, é pertinente o investimento no estudo dos biomarcadores, para que estes tenham a maior sensibilidade e especificidade no prognóstico e na predição de resposta às terapêuticas.

A biópsia líquida no cancro da próstata é já hoje uma realidade na prática clínica, com a quantificação de CTCs aprovada pela FDA para a monitorização do mCRPC. Com certeza que esta aprovação abrirá portas para futuras aprovações na inclusão de mais biomarcadores. Claramente que o seu papel é mais efetivo na doença disseminada, o que se justifica pela maior quantidade de biomarcadores em circulação nos estadios mais avançados da doença. Assim, a biópsia líquida constitui uma mais-valia para o follow-up destes doentes, podendo ser usada como uma variável contínua, que pode ser obtida de uma forma minimamente invasiva, em qualquer momento, através de uma colheita sanguínea. O resultado da análise destes biomarcadores fornece informação sobre o prognóstico dos doentes com cancro metastizado, assim como prediz a resposta à terapêutica.

O futuro assentará na perspetiva de se combinarem vários algoritmos diferentes e complementares na biópsia líquida, criando um painel de biomarcadores que funcionem como uma ferramenta com elevada acuidade prognóstica e preditiva de resposta ao tratamento, incluindo numa só análise a deteção e caracterização de CTCs, cftDNA, miRNAs e/ou exossomas, que poderá ser usada na monitorização minimamente invasiva dos doentes. Com o desenvolvimento de mais estudos clínicos, e a criação de um painel de biomarcadores com elevada especificidade e sensibilidade, a sua análise poderá também entrar nos protocolos de decisão terapêutica. Dessa forma, a escolha da terapêutica a instituir poderá ser feita forma mais personalizada e menos empírica, com o objetivo de aumentar a sobrevida livre de progressão e a sobrevida global dos doentes com cancro de próstata metastizado.

Apesar destas promessas, a biópsia líquida como ferramenta de diagnóstico, prognóstico, bem como o seu papel na predição de resposta aos tratamentos necessita ainda de ser validada em mais e maiores ensaios clínicos, sendo a próxima geração de estudos a chave para estabelecer definitivamente a aplicabilidade clínica destes biomarcadores, respondendo à questão central: As decisões terapêuticas baseadas nos resultados da biópsia líquida representarão uma melhoria significativa no curso da doença, com benefício para o doente? 


\begin{tabular}{|c|c|c|}
\hline Aplicação clínica & Análise do cfDNA & \\
\hline \multirow{4}{*}{ Diagnóstico } & Hipermetilação dos genes RASSF1, GSTP1 e RARB2 nos doentes com CaP (vs. indivíduos saudáveis) (92) & \multirow{4}{*}{$\begin{array}{l}\text { cfDNA como biomarcador de } \\
\text { diagnóstico no CaP }\end{array}$} \\
\hline & $\begin{array}{l}\text { Um painel de variações cromossómicas detetado permite discriminar doentes com CaP de indivíduos saudáveis, homens com } \\
\text { HBP e prostatite (93) }\end{array}$ & \\
\hline & Níveis mais elevados de cfDNA plasmáticos associados ao CaP (vs. HBP) (94) & \\
\hline & Níveis de cfDNA plasmáticos mais elevados em doentes com CaP (vs. indivíduos saudáveis) (95) & \\
\hline $\begin{array}{l}\text { Preditor de } \\
\text { recorrência }\end{array}$ & $\begin{array}{l}\text { Hipermetilação dos genes SRD5A2 e CYP11A1 nos doentes com CaP com recorrência bioquímica após prostatectomia radical } \\
\text { (96) }\end{array}$ & $\begin{array}{l}\text { Uma metilação aberrante do } \\
\text { cftDNA constitui um preditor } \\
\text { precoce de recorrência da doença }\end{array}$ \\
\hline \multirow{3}{*}{ Prognóstico } & $\begin{array}{l}\text { Concentrações crescentes de cftDNA nos doentes com mCRPC correlacionam-se com marcadores globais de carga tumoral (FA } \\
\text { e LDH), evolução clínica significativamente pior (33) e progressão imagiológica (36), constituindo um preditor independente de } \\
\text { sobrevida global (35) }\end{array}$ & \multirow{3}{*}{$\begin{array}{l}\text { O aparecimento de amplificações } \\
\text { focais de novo pode ser usado } \\
\text { como um biomarcador prognóstico } \\
\text { no follow-up dos doentes, } \\
\text { especialmente o ganho de cópias } \\
\text { do gene AR }\end{array}$} \\
\hline & $\begin{array}{l}\text { O surgimento de novas amplificações focais (gene AR e gene MYC) ocorre em } 40 \% \text { dos doentes com progressão metastática da } \\
\text { doença (41) }\end{array}$ & \\
\hline & Um elevado número de cópias do locus AR detetado no plasma de doentes com mCRPC, mas não em doentes com mCSPC (97) & \\
\hline \multirow{6}{*}{$\begin{array}{l}\text { Preditor de } \\
\text { resposta ao } \\
\text { tratamento }\end{array}$} & $\begin{array}{l}\text { Doentes com mCRPC com menores níveis de cftDNA têm melhor resposta à terapêutica com abiraterona (33) e enzalutamida } \\
\text { (34) (vs. doentes com níveis mais elevados de cftDNA) }\end{array}$ & \multirow{6}{*}{$\begin{array}{l}\text { Mutações e ganho do número de } \\
\text { cópias do gene AR associam-se } \\
\text { consistentemente a resistência à } \\
\text { abiraterona e à enzalutamida }\end{array}$} \\
\hline & Mutações no gene AR associadas a resistência à enzalutamida nos doentes com mCRPC $(46,47)$ & \\
\hline & $\begin{array}{l}\text { Ganhos no número de cópias do gene CYP17A1 e do gene AR associados aos doentes com mCRPC sob abiraterona com } \\
\text { sobrevida livre de progressão e sobrevida global mais curtas (vs. doentes com mCRPC sem ganho no número de cópias), } \\
\text { sugerindo que o ganho no número de cópias do gene AR ou do gene CYP17A1 pode ser usado como biomarcador preditivo de } \\
\text { resistência à abiraterona (45) }\end{array}$ & \\
\hline & Ganho no número de cópias do gene AR associa-se a resistência à abiraterona nos doentes com mCRPC (43) & \\
\hline & $\begin{array}{l}\text { Amplificações e mutações pontuais específicas do gene AR em doentes com mCRPC faz prever um pior desfecho se tratados } \\
\text { com abiraterona ou com enzalutamida (vs. tratamento com taxanos) (44) }\end{array}$ & \\
\hline & $\begin{array}{l}\text { Diminuição dos níveis plasmáticos de GSTP1 metilado após quimioterapia, sugerindo que a metilação do GSTP1 é um potencial } \\
\text { marcador de predição de resposta à quimioterapia (98) }\end{array}$ & \\
\hline
\end{tabular}


Tabela II. Frequência de genes alterados nos doentes com cancro da próstata metastizado

\begin{tabular}{|c|c|}
\hline Gene & Frequência \\
\hline \multirow[b]{3}{*}{$\begin{array}{l}\text { AR } \\
\text { (amplificações e mutações } \\
\text { pontuais -T8T8A, L702H) }\end{array}$} & $20 \%$ - 64,7\% (amplificações) $(37,40,42)$ \\
\hline & 22\% (mutações) (42) \\
\hline & $\begin{array}{l}48 \% \text { (mutações e/ou amplificações) na contagem } \\
\text { basal de doentes com mCRPC (34) } \\
60 \% \text { (mutações e/ou amplificações) na progressão de } \\
\text { doentes com mCRPC (34) }\end{array}$ \\
\hline SPOP & $8,8 \%(37)$ \\
\hline BRCA 2 & $5 \%-14 \%(38,39,42)$ \\
\hline ATM & $1,6 \%-10 \%(38,39)$ \\
\hline CHEK2 & $1,9 \%-6 \%(38,39)$ \\
\hline BRCA1 & $0,9 \%-6 \%(38,39,42)$ \\
\hline RAD51D & $0,4 \%(39)$ \\
\hline PALB2 & $0,4 \%(39)$ \\
\hline PTEN & $20 \%(40)$ \\
\hline PT53 & $36 \%(42)$ \\
\hline APC & $10 \%(42)$ \\
\hline NF1 & $9 \%(42)$ \\
\hline EGFR & $6 \%(42)$ \\
\hline CTNNB1 & $6 \%(42)$ \\
\hline ARID1A & $6 \%(42)$ \\
\hline PIK3CA & $5 \%(42)$ \\
\hline MYC & $20 \%(42)$ \\
\hline BRAF & $18 \%(42)$ \\
\hline
\end{tabular}


Tabela III: miRNAs identificados com potencial utilidade como biomarcadores no cancro da próstata [adaptado de Hoey (2019)] (99)

\begin{tabular}{|c|c|c|c|}
\hline miRNA & Expressão & Biomarcador & Efeito \\
\hline let-7a & $\downarrow$ & $\begin{array}{l}\text { Diagnóstico } \\
\text { Prognóstico }\end{array}$ & $\begin{array}{l}\text { Expressão diminuída no CaP (vs. HBP); } \\
\text { Expressão diminuída confere maior risco de progressão (67) }\end{array}$ \\
\hline miR-9* & $\uparrow$ & Prognóstico & Sobrexpressão nos doentes com CaP metastático (71) \\
\hline $\begin{array}{l}\text { Família miR- } \\
\text { 15a/miR-16-1 }\end{array}$ & $\downarrow / \varnothing$ & $\begin{array}{l}\text { Diagnóstico } \\
\text { Prognóstico }\end{array}$ & $\begin{array}{l}\text { Expressão diminuída nos doentes com CaP (vs. controlos saudáveis, doentes com prostatite crónica e HBP); Níveis muito baixos ou } \\
\text { inexistentes associados a estadios metastáticos (58) }\end{array}$ \\
\hline miR-20a & $\downarrow$ & $\begin{array}{l}\text { Preditivo } \\
\text { Prognóstico }\end{array}$ & Expressão diminuída (ou inalterada) após quimioterapia com docetaxel associada a pior sobrevida global (66) \\
\hline \multirow{4}{*}{ miR-21 } & $\uparrow$ & Prognóstico & Sobrexpressão nos doentes com CaP (vs. indivíduos saudáveis) (68) \\
\hline & $\uparrow$ & Prognóstico & Sobrexpressão em doentes com CaP em estadio mais avançado (64) \\
\hline & $\uparrow$ & $\begin{array}{l}\text { Diagnóstico } \\
\text { Prognóstico }\end{array}$ & $\begin{array}{l}\text { Sobrexpressão em doentes com CaP (vs. indivíduos saudáveis); Níveis mais elevados a associados a doença metastizada (vs. doença } \\
\text { localizada) (63) }\end{array}$ \\
\hline & $\uparrow$ & Preditivo & Sobrexpressão nos doentes com mCRPC; Níveis mais elevados associados a resistência ao docetaxel (65) \\
\hline miR-24 & $\downarrow$ & Prognóstico & Diminuído no CaP (indivíduos saudáveis>baixo risco>risco intermédio>alto risco) (69) \\
\hline miR-93 & $\uparrow$ & $\begin{array}{l}\text { Diagnóstico } \\
\text { Prognóstico }\end{array}$ & $\begin{array}{l}\text { Sobrexpressão no CaP (vs. indivíduos saudáveis). } \\
\text { Níveis progressivamente mais elevados nos tumores mais agressivos (69) }\end{array}$ \\
\hline \multirow{3}{*}{ miR-106a } & $\uparrow$ & Prognóstico & Sobrexpressão no CaP agressivo (vs. CaP indolente) (100) \\
\hline & $\uparrow$ & Prognóstico & Aumentado no CaP:(alto risco >risco intermédio>baixo risco>indivíduos saudáveis) (69) \\
\hline & $\uparrow$ & Diagnóstico & Constitui uma assinatura de miRNAs que permite distinguir CaP e HBP em doentes com PSA elevado (70) \\
\hline $\operatorname{miR}-106 b$ & $\uparrow$ & Diagnóstico & Sobrexpressão nos doentes com CaP (vs. indivíduos saudáveis) (68) \\
\hline miR-130b & $\downarrow$ & Diagnóstico & Constitui uma assinatura de miRNAs que permite distinguir CaP e HBP em doentes com PSA elevado (70) \\
\hline miR-135a* & $\downarrow$ & Prognóstico & Expressão diminuída no CaP agressivo (vs. CaP indolente) (100) \\
\hline \multirow{6}{*}{ miR-141 } & $\uparrow$ & Diagnóstico & Sobrexpressão no CaP (vs HBP) (67) \\
\hline & $\uparrow$ & Prognóstico & Sobrexpressão nos doentes com CaP metastizado (71) \\
\hline & $\uparrow$ & Prognóstico & $\begin{array}{l}\text { Sobrexpressão nos doentes com metástases ósseas, com níveis mais elevados a correlacionarem-se com a presença de mais de } \\
\text { lesões (74) }\end{array}$ \\
\hline & $\uparrow$ & Prognóstico & Sobrexpressão no mCRPC (vs. CaP localizado de baixo risco) (73) \\
\hline & $\uparrow$ & Prognóstico & $\begin{array}{l}\text { Sobrexpressão em doentes com CaP (vs. indivíduos saudáveis), com níveis mais elevados a associarem-se a doença metastizada (vs. } \\
\text { doença localizada) (63) }\end{array}$ \\
\hline & $\uparrow$ & Diagnóstico & Sobrexpressão nos doentes com CaP (vs. indivíduos saudáveis) (68) \\
\hline
\end{tabular}




\begin{tabular}{|c|c|c|c|}
\hline miR-146a & $\downarrow$ & $\begin{array}{l}\text { Preditivo } \\
\text { Prognóstico }\end{array}$ & Subexpressão previamente à quimioterapia com docetaxel associada a não resposta do PSA dos doentes com mCRPC (66) \\
\hline $\begin{array}{l}\text { Família miR- } \\
200\end{array}$ & $\uparrow$ & $\begin{array}{l}\text { Preditivo } \\
\text { Prognóstico }\end{array}$ & $\begin{array}{l}\text { Sobrexpressão previamente à quimioterapia com docetaxel associa-se a resistência à terapêutica e menor sobrevida nos doentes } \\
\text { com mCRPC (66) }\end{array}$ \\
\hline miR-221 & $\uparrow$ & $\begin{array}{l}\text { Diagnóstico } \\
\text { Prognóstico }\end{array}$ & $\begin{array}{l}\text { Sobrexpressão em doentes com CaP (vs. indivíduos saudáveis), com níveis mais elevados a associar-se a doença metastizada (vs. } \\
\text { doença localizada) (63) }\end{array}$ \\
\hline miR-222 & $\stackrel{\downarrow}{\uparrow}$ & $\begin{array}{l}\text { Preditivo } \\
\text { Prognóstico }\end{array}$ & $\begin{array}{l}\text { Dependendo do contexto, o miR-222 pode ter funções oncogénicas ou supressoras tumorais. Daí que tanto a sua subexpressão ou } \\
\text { sobrexpressão possam ter resultados adversos: Subexpressão previamente à quimioterapia com docetaxel associa-se a fraca } \\
\text { resposta do PSA nos doentes com mCRPC; Sobrexpressão resulta em proliferação celular (66) }\end{array}$ \\
\hline \multirow[t]{2}{*}{ miR-223 } & $\downarrow$ & $\begin{array}{l}\text { Prognóstico } \\
\text { Diagnóstico }\end{array}$ & $\begin{array}{l}\text { Dependendo do contexto, o miR-223 pode ter funções oncogénicas ou supressoras tumorais. Daí que tanto a sua subexpressão ou } \\
\text { sobrexpressão possam ter resultados adversos: Subexpresso no CaP (vs. indivíduos saudáveis); Sobrexpresso nos tumores de alto risco } \\
\text { vs. baixo risco (69) }\end{array}$ \\
\hline & $\downarrow$ & Diagnóstico & Faz parte de uma assinatura de miRNAs que permite distinguir CaP e HBP em doentes com PSA elevado (70) \\
\hline miR-301b & $\uparrow$ & $\begin{array}{l}\text { Preditivo } \\
\text { Prognóstico }\end{array}$ & Sobrexpressão previamente à quimioterapia com docetaxel associa-se a fraca resposta do PSA nos doentes com mCRPC (66) \\
\hline \multirow{3}{*}{ miR-375 } & 个 & Prognóstico & Sobrexpressão nos doentes com CaP metastático (71) \\
\hline & 个 & Prognóstico & Sobrexpressão nos tumores de alto risco e no mCRPC (vs tumores de baixo risco) (73) \\
\hline & $\uparrow$ & Diagnóstico & Sobrexpressão nos doentes com CaP (vs. indivíduos saudáveis) (68) \\
\hline miR-378 & $\uparrow$ & Prognóstico & Sobrexpressão nos tumores de alto risco e no mCRPC (vs. tumores localizados de baixo risco) (73) \\
\hline miR-409-3p & $\downarrow$ & Prognóstico & Expressão diminuída no mCRPC (vs. CaP localizado de baixo risco) (73) \\
\hline miR-429 & $\uparrow$ & $\begin{array}{l}\text { Prognóstico } \\
\text { Preditivo }\end{array}$ & $\begin{array}{l}\text { Sobrexpressão previamente à quimioterapia com docetaxel associa-se a resistência à terapêutica e menor sobrevida nos doentes } \\
\text { com mCRPC (66) }\end{array}$ \\
\hline miR-433 & $\uparrow$ & Prognóstico & Sobrexpressão no CaP agressivo (vs. CaP indolente) (100) \\
\hline miR-451 & $\uparrow$ & $\begin{array}{l}\text { Diagnóstico } \\
\text { Prognóstico }\end{array}$ & Sobrexpressão nos tumores de alto risco (vs. indivíduos saudáveis) (69) \\
\hline miR-561a-3p & $\uparrow$ & Prognóstico & Sobrexpressão nos doentes com CaP metastático (71) \\
\hline
\end{tabular}


Tabela IV. Assinaturas de miRNAs e potencial utilidade do cancro da próstata

\begin{tabular}{|c|c|c|}
\hline Assinaturas de miRNAs & & Resultados \\
\hline miR-24 + miR-223 & $\downarrow$ & Distinção entre CaP indolente vs CaP agressivo em doentes em vigilância ativa; \\
\hline miR-375 & $\uparrow$ & Os autores sugerem usar esta assinatura de 3 mi-RNAs + PSA para detetar doença agressiva (101) \\
\hline miR-106a + miR-433 & $\uparrow$ & Distinção entre CaP agressivo de muito alto risco (vs. CaP indolente) (100) \\
\hline miR-135a* + miR-200c + miR-605 & $\downarrow$ & \\
\hline miR-24 + miR-223 & $\downarrow$ & Distinção entre doentes com CaP vs. Indivíduos saudáveis (69) \\
\hline miR-93 + miR-106a +miR-451 & $\uparrow$ & \\
\hline Rácios: & 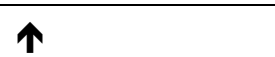 & Distinção entre doentes com CaP e doentes com HBP (com PSA elevado) (70) \\
\hline miR-106a/miR-130b & [rácios mais elevados & \\
\hline $\mathrm{miR}-106 \mathrm{a} / \mathrm{miR}-223$ & associam-se a CaP] & \\
\hline miR-20a, miR-21 e miR-145 & $\uparrow$ & Distinção entre doentes com risco intermédio vs. baixo risco (score D'Amico) (64) \\
\hline miR-20a, miR-21, miR-145 e miR-221 & $\uparrow$ & Distinção entre doentes com alto risco vs. baixo risco (score D'Amico) (64) \\
\hline $\begin{array}{l}\text { miR-200a + miR-200b + miR-429 } \\
\text { (família miR-200) }\end{array}$ & $\uparrow$ & $\begin{array}{l}\text { A sobrexpressão da família miR-200 detetada antes de se instituir o tratamento com docetaxel é preditiva de pior } \\
\text { sobrevida global nos doentes mCRPC, com resistência ao tratamento com docetaxel (66) }\end{array}$ \\
\hline $\begin{array}{l}\text { miR-375 + miR-378* + miR-141 } \\
\text { miR-409-3p }\end{array}$ & $\uparrow$ & Distinção entre mCRPC (vs. CaP localizado de baixo risco) (73) \\
\hline $\begin{array}{l}\text { miR-96 + miR-183 } \\
\text { miR-145 + miR-221 }\end{array}$ & $\uparrow$ & $\begin{array}{l}\text { Distinção entre CaP e controlos saudáveis; } \\
\text { Maior agressividade tumoral; } \\
\text { Maior risco de metastização; } \\
\text { Pior sobrevida global (72) }\end{array}$ \\
\hline miR-15 + miR-16 & $\downarrow$ & Predição de um pior prognóstico no CaP (60) \\
\hline miR-21 & $\uparrow$ & \\
\hline miR-141, miR-21, e miR-375 & $\uparrow$ & Distinção entre doentes com CaP e saudáveis (68) \\
\hline
\end{tabular}

CaP - Cancro da Próstata; HBP - Hiperplasia Benigna da Próstata; mCRPC - Cancro da próstata metastizado resistente à castração; PSA - Antigénio Específico da Próstata 


\section{Bibliografia}

1. Bray F, Ferlay J, Soerjomataram I, Siegel RL, Torre LA, Jemal A. Global cancer statistics 2018: GLOBOCAN estimates of incidence and mortality worldwide for 36 cancers in 185 countries. CA Cancer J Clin. 2018;68(6):394-424.

2. Vandekerkhove G, Chi KN, Wyatt AW. Clinical utility of emerging liquid biomarkers in advanced prostate cancer. Cancer Genet. 2018;228-229:151-8.

3. Morrison GJ, Goldkorn A. Development and Application of Liquid Biopsies in Metastatic Prostate Cancer. Curr Oncol Rep. 2018;20(4):35.

4. Riaz IB, Wang L, Kohli M. Liquid biopsy approach in the management of prostate cancer. Transl Res. 2018.

5. Hegemann M, Stenzl A, Bedke J, Chi KN, Black PC, Todenhofer T. Liquid biopsy: ready to guide therapy in advanced prostate cancer? BJU Int. 2016;118(6):855-63.

6. Ashworth T. A case of cancer in which cells similar to those in the tumors were seen in the blood after death. Aust Med J. 1869;14:146-9.

7. Zainfeld D, Goldkorn A. Liquid Biopsy in Prostate Cancer: Circulating Tumor Cells and Beyond. Cancer Treat Res. 2018;175:87-104.

8. Alix-Panabieres C, Pantel K. Technologies for detection of circulating tumor cells: facts and vision. Lab Chip. 2014;14(1):57-62.

9. de Bono JS, Scher HI, Montgomery RB, Parker C, Miller MC, Tissing H, et al. Circulating tumor cells predict survival benefit from treatment in metastatic castration-resistant prostate cancer. Clin Cancer Res. 2008;14(19):6302-9.

10. Okegawa T, Nutahara K, Higashihara E. Immunomagnetic quantification of circulating tumor cells as a prognostic factor of androgen deprivation responsiveness in patients with hormone naive metastatic prostate cancer. J Urol. 2008;180(4):1342-7.

11. Goldkorn A PM, Agarwal N, Hussain M, Lara P, Vaena DA, et al. Circulating tumor cells (CTCS) in SWOG S1216: A phase 3 multicenter trial in metastatic hormone sensitive prostate cancer (mHSPC). J Clin Oncol. 2016;34.

12. Goodman OB, Jr., Symanowski JT, Loudyi A, Fink LM, Ward DC, Vogelzang NJ. Circulating tumor cells as a predictive biomarker in patients with hormone-sensitive prostate cancer. Clin Genitourin Cancer. 2011;9(1):31-8.

13. Lorente D, Olmos D, Mateo J, Bianchini D, Seed G, Fleisher M, et al. Decline in Circulating Tumor Cell Count and Treatment Outcome in Advanced Prostate Cancer. Eur Urol. 2016;70(6):985-92.

14. Goldkorn A, Ely B, Quinn DI, Tangen CM, Fink LM, Xu T, et al. Circulating tumor cell counts are prognostic of overall survival in SWOG S0421: a phase III trial of docetaxel with or without atrasentan for metastatic castration-resistant prostate cancer. J Clin Oncol. 2014;32(11):1136-42. 15. Scher HI, Heller G, Molina A, Attard G, Danila DC, Jia X, et al. Circulating tumor cell biomarker panel as an individual-level surrogate for survival in metastatic castration-resistant prostate cancer. J Clin Oncol. 2015;33(12):1348-55.

16. Magbanua MJ, Sosa EV, Scott JH, Simko J, Collins C, Pinkel D, et al. Isolation and genomic analysis of circulating tumor cells from castration resistant metastatic prostate cancer. BMC Cancer. 2012;12:78.

17. Jiang Y, Palma JF, Agus DB, Wang Y, Gross ME. Detection of androgen receptor mutations in circulating tumor cells in castration-resistant prostate cancer. Clin Chem. 2010;56(9):1492-5.

18. Darshan MS, Loftus MS, Thadani-Mulero M, Levy BP, Escuin D, Zhou XK, et al. Taxaneinduced blockade to nuclear accumulation of the androgen receptor predicts clinical responses in metastatic prostate cancer. Cancer Res. 2011;71(18):6019-29.

19. Antonarakis ES, Lu C, Wang H, Luber B, Nakazawa M, Roeser JC, et al. AR-V7 and resistance to enzalutamide and abiraterone in prostate cancer. N Engl J Med. 2014;371(11):102838. 
20. De Laere B, van Dam PJ, Whitington T, Mayrhofer M, Diaz EH, Van den Eynden G, et al. Comprehensive Profiling of the Androgen Receptor in Liquid Biopsies from Castration-resistant Prostate Cancer Reveals Novel Intra-AR Structural Variation and Splice Variant Expression Patterns. Eur Urol. 2017; 72(2):192-200.

21. Antonarakis ES, Lu C, Luber B, Wang H, Chen Y, Nakazawa M, et al. Androgen Receptor Splice Variant 7 and Efficacy of Taxane Chemotherapy in Patients With Metastatic CastrationResistant Prostate Cancer. JAMA Oncol. 2015;1(5):582-91.

22. Antonarakis ES, Lu C, Luber B, Wang H, Chen Y, Zhu Y, et al. Clinical Significance of Androgen Receptor Splice Variant-7 mRNA Detection in Circulating Tumor Cells of Men With Metastatic Castration-Resistant Prostate Cancer Treated With First- and Second-Line Abiraterone and Enzalutamide. J Clin Oncol. 2017;35(19):2149-56.

23. Onstenk W, Sieuwerts AM, Kraan J, Van M, Nieuweboer AJ, Mathijssen RH, et al. Efficacy of Cabazitaxel in Castration-resistant Prostate Cancer Is Independent of the Presence of AR-V7 in Circulating Tumor Cells. Eur Urol. 2015;68(6):939-45.

24. McDaniel AS, Ferraldeschi R, Krupa R, Landers M, Graf R, Louw J, et al. Phenotypic diversity of circulating tumour cells in patients with metastatic castration-resistant prostate cancer. BJU Int. 2017;120(5B):E30-E44.

25. Scher HI, Graf RP, Schreiber NA, McLaughlin B, Jendrisak A, Wang Y, et al. Phenotypic Heterogeneity of Circulating Tumor Cells Informs Clinical Decisions between AR Signaling Inhibitors and Taxanes in Metastatic Prostate Cancer. Cancer Res. 2017;77(20):5687-98.

26. Attard G, Swennenhuis JF, Olmos D, Reid AH, Vickers E, A'Hern R, et al. Characterization of ERG, AR and PTEN gene status in circulating tumor cells from patients with castration-resistant prostate cancer. Cancer Res. 2009;69(7):2912-8.

27. Reig O, Marin-Aguilera M, Carrera G, Jimenez N, Pare L, Garcia-Recio S, et al. TMPRSS2ERG in Blood and Docetaxel Resistance in Metastatic Castration-resistant Prostate Cancer. Eur Urol. 2016;70(5):709-13.

28. Punnoose EA, Ferraldeschi R, Szafer-Glusman E, Tucker EK, Mohan S, Flohr P, et al. PTEN loss in circulating tumour cells correlates with PTEN loss in fresh tumour tissue from castrationresistant prostate cancer patients. Br J Cancer. 2015;113(8):1225-33.

29. Goldkorn A, Ely B, Tangen CM, Tai YC, Xu T, Li H, et al. Circulating tumor cell telomerase activity as a prognostic marker for overall survival in SWOG 0421: a phase III metastatic castration resistant prostate cancer trial. Int J Cancer. 2015;136(8):1856-62.

30. Xu T, Lu B, Tai YC, Goldkorn A. A cancer detection platform which measures telomerase activity from live circulating tumor cells captured on a microfilter. Cancer Res. 2010;70(16):64206.

31. Marrugo-Ramirez J, Mir M, Samitier J. Blood-Based Cancer Biomarkers in Liquid Biopsy: A Promising Non-Invasive Alternative to Tissue Biopsy. Int J Mol Sci. 2018;19(10).

32. Wroclawski ML, Serpa-Neto A, Fonseca FL, Castro-Neves-Neto O, Pompeo AS, Machado $\mathrm{MT}$, et al. Cell-free plasma DNA as biochemical biomarker for the diagnosis and follow-up of prostate cancer patients. Tumour Biol. 2013;34(5):2921-7.

33. Romanel A, Gasi Tandefelt D, Conteduca V, Jayaram A, Casiraghi N, Wetterskog D, et al. Plasma AR and abiraterone-resistant prostate cancer. Sci Transl Med. 2015;7(312):312re10.

34. Wyatt AW, Azad AA, Volik SV, Annala M, Beja K, McConeghy B, et al. Genomic Alterations in Cell-Free DNA and Enzalutamide Resistance in Castration-Resistant Prostate Cancer. JAMA Oncol. 2016;2(12):1598-606.

35. Kienel A, Porres D, Heidenreich A, Pfister D. cfDNA as a Prognostic Marker of Response to Taxane Based Chemotherapy in Patients with Prostate Cancer. J Urol. 2015;194(4):966-71.

36. Kwee S, Song M-A, Cheng I, Loo L, Tiirikainen M. Measurement of Circulating Cell-Free DNA in Relation to 18F-Fluorocholine PET/CT Imaging in Chemotherapy-Treated Advanced Prostate Cancer. Clinical and Translational Science. 2012;5(1):65-70. 
37. Wyatt AW, Annala M, Aggarwal R, Beja K, Feng F, Youngren J, et al. Concordance of Circulating Tumor DNA and Matched Metastatic Tissue Biopsy in Prostate Cancer. J Natl Cancer Inst. 2017;109(12).

38. Mateo J, Carreira S, Sandhu S, Miranda S, Mossop H, Perez-Lopez R, et al. DNA-Repair Defects and Olaparib in Metastatic Prostate Cancer. N Engl J Med. 2015;373(18):1697-708.

39. Pritchard CC, Mateo J, Walsh MF, De Sarkar N, Abida W, Beltran H, et al. Inherited DNARepair Gene Mutations in Men with Metastatic Prostate Cancer. N Engl J Med. 2016;375(5):44353.

40. Xia S, Kohli M, Du M, Dittmar RL, Lee A, Nandy D, et al. Plasma genetic and genomic abnormalities predict treatment response and clinical outcome in advanced prostate cancer. Oncotarget. 2015;6(18):16411-21.

41. Ulz P, Belic J, Graf R, Auer M, Lafer I, Fischereder K, et al. Whole-genome plasma sequencing reveals focal amplifications as a driving force in metastatic prostate cancer. Nat Commun. 2016;7:12008.

42. Sonpavde G, Agarwal N, Pond GR, Nagy RJ, Nussenzveig RH, Hahn AW, et al. Circulating tumor DNA alterations in patients with metastatic castration-resistant prostate cancer. Cancer. 2019.

43. Carreira S, Romanel A, Goodall J, Grist E, Ferraldeschi R, Miranda S, et al. Tumor clone dynamics in lethal prostate cancer. Sci Transl Med. 2014;6(254):254ra125.

44. Conteduca V, Wetterskog D, Sharabiani MTA, Grande E, Fernandez-Perez MP, Jayaram A, et al. Androgen receptor gene status in plasma DNA associates with worse outcome on enzalutamide or abiraterone for castration-resistant prostate cancer: a multi-institution correlative biomarker study. Ann Oncol. 2017;28(7):1508-16.

45. Salvi S, Casadio V, Conteduca V, Burgio SL, Menna C, Bianchi E, et al. Circulating cell-free $A R$ and CYP17A1 copy number variations may associate with outcome of metastatic castrationresistant prostate cancer patients treated with abiraterone. Br J Cancer. 2015;112(10):1717-24. 46. Lallous N, Volik SV, Awrey S, Leblanc E, Tse R, Murillo J, et al. Functional analysis of androgen receptor mutations that confer anti-androgen resistance identified in circulating cellfree DNA from prostate cancer patients. Genome Biol. 2016;17:10.

47. Azad AA, Volik SV, Wyatt AW, Haegert A, Le Bihan S, Bell RH, et al. Androgen Receptor Gene Aberrations in Circulating Cell-Free DNA: Biomarkers of Therapeutic Resistance in Castration-Resistant Prostate Cancer. Clin Cancer Res. 2015;21(10):2315-24.

48. Seitz AK, Thoene S, Bietenbeck A, Nawroth R, Tauber R, Thalgott M, et al. AR-V7 in Peripheral Whole Blood of Patients with Castration-resistant Prostate Cancer: Association with Treatment-specific Outcome Under Abiraterone and Enzalutamide. Eur Urol. 2017;72(5):828-34. 49. Robinson D, Van Allen EM, Wu YM, Schultz N, Lonigro RJ, Mosquera JM, et al. Integrative clinical genomics of advanced prostate cancer. Cell. 2015;161(5):1215-28.

50. Kumar A, Coleman I, Morrissey C, Zhang X, True LD, Gulati R, et al. Substantial interindividual and limited intraindividual genomic diversity among tumors from men with metastatic prostate cancer. Nat Med. 2016;22(4):369-78.

51. Annala M, Struss WJ, Warner EW, Beja K, Vandekerkhove G, Wong A, et al. Treatment Outcomes and Tumor Loss of Heterozygosity in Germline DNA Repair-deficient Prostate Cancer. Eur Urol. 2017;72(1):34-42.

52. Fong PC, Boss DS, Yap TA, Tutt A, Wu P, Mergui-Roelvink M, et al. Inhibition of poly(ADPribose) polymerase in tumors from BRCA mutation carriers. N Engl J Med. 2009;361(2):123-34.

53. Goodall J, Mateo J, Yuan W, Mossop H, Porta N, Miranda S, et al. Circulating Cell-Free DNA to Guide Prostate Cancer Treatment with PARP Inhibition. Cancer Discov. 2017;7(9):1006-17.

54. Lee RC, Feinbaum RL, Ambros V. The C. elegans heterochronic gene lin-4 encodes small RNAs with antisense complementarity to lin-14. Cell. 1993;75(5):843-54.

55. Kozomara A, Birgaoanu M, Griffiths-Jones S. miRBase: from microRNA sequences to function. Nucleic Acids Res. 2019;47(D1):D155-D62.

56. Ambros V. The functions of animal microRNAs. Nature. 2004;431(7006):350-5. 
57. Volinia S, Calin GA, Liu CG, Ambs S, Cimmino A, Petrocca F, et al. A microRNA expression signature of human solid tumors defines cancer gene targets. Proc Natl Acad Sci U S A. 2006;103(7):2257-61.

58. Zidan HE, Abdul-Maksoud RS, Elsayed WSH, Desoky EAM. Diagnostic and prognostic value of serum miR-15a and miR-16-1 expression among egyptian patients with prostate cancer. IUBMB Life. 2018;70(5):437-44.

59. Musumeci M, Coppola V, Addario A, Patrizii M, Maugeri-Sacca M, Memeo L, et al. Control of tumor and microenvironment cross-talk by miR-15a and miR-16 in prostate cancer. Oncogene. 2011;30(41):4231-42.

60. Bonci D, De Maria R. miR-15/miR-16 loss, miR-21 upregulation, or deregulation of their target genes predicts poor prognosis in prostate cancer patients. Mol Cell Oncol. 2016;3(4):e1109744.

61. Jin W, Chen F, Wang K, Song Y, Fei X, Wu B. miR-15a/miR-16 cluster inhibits invasion of prostate cancer cells by suppressing TGF-beta signaling pathway. Biomed Pharmacother. 2018;104:637-44.

62. Hasegawa T, Glavich GJ, Pahuski M, Short A, Semmes OJ, Yang L, et al. Characterization and Evidence of the miR-888 Cluster as a Novel Cancer Network in Prostate. Mol Cancer Res. 2018;16(4):669-81.

63. Yaman Agaoglu F, Kovancilar M, Dizdar Y, Darendeliler E, Holdenrieder S, Dalay N, et al. Investigation of miR-21, miR-141, and miR-221 in blood circulation of patients with prostate cancer. Tumour Biol. 2011;32(3):583-8.

64. Shen J, Hruby GW, McKiernan JM, Gurvich I, Lipsky MJ, Benson MC, et al. Dysregulation of circulating microRNAs and prediction of aggressive prostate cancer. Prostate. 2012;72(13):1469-

77.

65. Zhang HL, Yang LF, Zhu Y, Yao XD, Zhang SL, Dai B, et al. Serum miRNA-21: elevated levels in patients with metastatic hormone-refractory prostate cancer and potential predictive factor for the efficacy of docetaxel-based chemotherapy. Prostate. 2011;71(3):326-31.

66. Lin HM, Castillo L, Mahon KL, Chiam K, Lee BY, Nguyen Q, et al. Circulating microRNAs are associated with docetaxel chemotherapy outcome in castration-resistant prostate cancer. $\mathrm{Br} \mathrm{J}$

Cancer. 2014;110(10):2462-71.

67. Kelly BD, Miller N, Sweeney KJ, Durkan GC, Rogers E, Walsh K, et al. A Circulating MicroRNA Signature as a Biomarker for Prostate Cancer in a High Risk Group. J Clin Med. 2015;4(7):1369-79.

68. Porzycki P, Ciszkowicz E, Semik M, Tyrka M. Combination of three miRNA (miR-141, miR21, and miR-375) as potential diagnostic tool for prostate cancer recognition. Int Urol Nephrol. 2018;50(9):1619-26.

69. Moltzahn F, Olshen AB, Baehner L, Peek A, Fong L, Stoppler H, et al. Microfluidic-based multiplex qRT-PCR identifies diagnostic and prognostic microRNA signatures in the sera of prostate cancer patients. Cancer Res. 2011;71(2):550-60.

70. Sharova E, Grassi A, Marcer A, Ruggero K, Pinto F, Bassi P, et al. A circulating miRNA assay as a first-line test for prostate cancer screening. Br J Cancer. 2016;114(12):1362-6.

71. Brase JC, Johannes M, Schlomm T, Falth M, Haese A, Steuber T, et al. Circulating miRNAs are correlated with tumor progression in prostate cancer. Int J Cancer. 2011;128(3):608-16.

72. Larne O, Martens-Uzunova E, Hagman Z, Edsjo A, Lippolis G, den Berg MS, et al. miQ--a novel microRNA based diagnostic and prognostic tool for prostate cancer. Int J Cancer. 2013;132(12):2867-75.

73. Nguyen HC, Xie W, Yang M, Hsieh CL, Drouin S, Lee GS, et al. Expression differences of circulating microRNAs in metastatic castration resistant prostate cancer and low-risk, localized prostate cancer. Prostate. 2013;73(4):346-54.

74. Zhang HL, Qin XJ, Cao DL, Zhu Y, Yao XD, Zhang SL, et al. An elevated serum miR-141 level in patients with bone-metastatic prostate cancer is correlated with more bone lesions. Asian J Androl. 2013;15(2):231-5. 
75. Lin HM, Nikolic I, Yang J, Castillo L, Deng N, Chan CL, et al. MicroRNAs as potential therapeutics to enhance chemosensitivity in advanced prostate cancer. Sci Rep. 2018;8(1):7820.

76. Epis MR, Giles KM, Beveridge DJ, Richardson KL, Candy PA, Stuart LM, et al. miR-331-3p and Aurora Kinase inhibitor II co-treatment suppresses prostate cancer tumorigenesis and progression. Oncotarget. 2017;8(33):55116-34.

77. Minciacchi VR, Zijlstra A, Rubin MA, Di Vizio D. Extracellular vesicles for liquid biopsy in prostate cancer: where are we and where are we headed? Prostate Cancer Prostatic Dis. 2017;20(3):251-8.

78. Shah R, Patel T, Freedman JE. Circulating Extracellular Vesicles in Human Disease. N Engl J Med. 2018;379(10):958-66.

79. Pan B-T, Johnstone RM. Fate of the transferrin receptor during maturation of sheep reticulocytes in vitro: Selective externalization of the receptor. Cell. 1983;33(3):967-78.

80. O'Driscoll L. Expanding on exosomes and ectosomes in cancer. N Engl J Med. 2015;372(24):2359-62.

81. Logozzi M, Angelini DF, lessi E, Mizzoni D, Di Raimo R, Federici C, et al. Increased PSA expression on prostate cancer exosomes in in vitro condition and in cancer patients. Cancer Lett. 2017;403:318-29.

82. McKiernan J, Donovan MJ, O'Neill V, Bentink S, Noerholm M, Belzer S, et al. A Novel Urine Exosome Gene Expression Assay to Predict High-grade Prostate Cancer at Initial Biopsy. JAMA Oncol. 2016;2(7):882-9.

83. Gabriel K, Ingram A, Austin R, Kapoor A, Tang D, Majeed F, et al. Regulation of the tumor suppressor PTEN through exosomes: a diagnostic potential for prostate cancer. PLoS One. 2013;8(7):e70047.

84. Giulietti M, Santoni M, Cimadamore A, Carrozza F, Piva F, Cheng L, et al. Exploring Small Extracellular Vesicles for Precision Medicine in Prostate Cancer. Front Oncol. 2018;8:221.

85. Sanchez CA, Andahur EI, Valenzuela R, Castellon EA, Fulla JA, Ramos CG, et al. Exosomes from bulk and stem cells from human prostate cancer have a differential microRNA content that contributes cooperatively over local and pre-metastatic niche. Oncotarget. 2016;7(4):3993-4008. 86. Huang X, Yuan T, Liang M, Du M, Xia S, Dittmar R, et al. Exosomal miR-1290 and miR-375 as prognostic markers in castration-resistant prostate cancer. Eur Urol. 2015;67(1):33-41.

87. Bhagirath D, Yang TL, Bucay N, Sekhon K, Majid S, Shahryari V, et al. microRNA-1246 Is an Exosomal Biomarker for Aggressive Prostate Cancer. Cancer Res. 2018;78(7):1833-44.

88. Endzelins E, Berger A, Melne V, Bajo-Santos C, Sobolevska K, Abols A, et al. Detection of circulating miRNAs: comparative analysis of extracellular vesicle-incorporated miRNAs and cellfree miRNAs in whole plasma of prostate cancer patients. BMC Cancer. 2017;17(1):730.

89. Kharaziha $P$, Chioureas D, Rutishauser D, Baltatzis $G$, Lennartsson L, Fonseca $P$, et al. Molecular profiling of prostate cancer derived exosomes may reveal a predictive signature for response to docetaxel. Oncotarget. 2015;6(25):21740-54.

90. Del Re M, Biasco E, Crucitta S, Derosa L, Rofi E, Orlandini C, et al. The Detection of Androgen Receptor Splice Variant 7 in Plasma-derived Exosomal RNA Strongly Predicts Resistance to Hormonal Therapy in Metastatic Prostate Cancer Patients. Eur Urol. 2017;71(4):680-7.

91. Di Meo A, Bartlett J, Cheng Y, Pasic MD, Yousef GM. Liquid biopsy: a step forward towards precision medicine in urologic malignancies. Mol Cancer. 2017;16(1):80.

92. Sunami E, Shinozaki M, Higano CS, Wollman R, Dorff TB, Tucker SJ, et al. Multimarker circulating DNA assay for assessing blood of prostate cancer patients. Clin Chem. 2009;55(3):55967.

93. Schutz E, Akbari MR, Beck J, Urnovitz H, Zhang WW, Bornemann-Kolatzki K, et al. Chromosomal instability in cell-free DNA is a serum biomarker for prostate cancer. Clin Chem. 2015;61(1):239-48.

94. Chun FK, Muller I, Lange I, Friedrich MG, Erbersdobler A, Karakiewicz PI, et al. Circulating tumour-associated plasma DNA represents an independent and informative predictor of prostate cancer. BJU Int. 2006;98(3):544-8. 
95. Altimari A, Grigioni AD, Benedettini E, Gabusi E, Schiavina R, Martinelli A, et al. Diagnostic role of circulating free plasma DNA detection in patients with localized prostate cancer. Am J Clin Pathol. 2008;129(5):756-62.

96. Horning AM, Awe JA, Wang CM, Liu J, Lai Z, Wang VY, et al. DNA methylation screening of primary prostate tumors identifies SRD5A2 and CYP11A1 as candidate markers for assessing risk of biochemical recurrence. Prostate. 2015;75(15):1790-801.

97. Heitzer E, Ulz P, Belic J, Gutschi S, Quehenberger F, Fischereder K, et al. Tumor-associated copy number changes in the circulation of patients with prostate cancer identified through wholegenome sequencing. Genome Med. 2013;5(4):30.

98. Mahon KL, Qu W, Devaney J, Paul C, Castillo L, Wykes RJ, et al. Methylated Glutathione Stransferase 1 (mGSTP1) is a potential plasma free DNA epigenetic marker of prognosis and response to chemotherapy in castrate-resistant prostate cancer. Br J Cancer. 2014;111(9):1802-9. 99. Hoey C, Liu SK. Circulating blood miRNAs for prostate cancer risk stratification: miRroring the underlying tumor biology with liquid biopsies. Res Rep Urol. 2019;11:29-42.

100. Alhasan AH, Scott AW, Wu JJ, Feng G, Meeks JJ, Thaxton CS, et al. Circulating microRNA signature for the diagnosis of very high-risk prostate cancer. Proc Natl Acad Sci U S A. 2016;113(38):10655-60.

101. Liu RSC, Olkhov-Mitsel E, Jeyapala R, Zhao F, Commisso K, Klotz L, et al. Assessment of Serum microRNA Biomarkers to Predict Reclassification of Prostate Cancer in Patients on Active Surveillance. J Urol. 2018;199(6):1475-81. 